www.mdpi.com/journal/applsci

Article

\title{
Synthesis of Cascadable DDCC-Based Universal Filter Using NAM
}

\section{Huu-Duy Tran ${ }^{1,2}$, Hung-Yu Wang ${ }^{1, *}$, Min-Chuan Lin $^{3}$ and Quoc-Minh Nguyen ${ }^{1}$}

1 Department of Electronic Engineering, National Kaohsiung University of Applied Sciences, Kaohsiung 807, Taiwan; E-Mails: duyth@dlu.edu.vn (H.-D.T.); minhoba@ymail.com (Q.-M.N.)

2 Department of Physics, University of Dalat, Dalat City, Vietnam

3 Department of Electronic Engineering, Kun Shan University, Tainan 710, Taiwan; E-Mail: mc.lin@seed.net.tw

* Author to whom correspondence should be addressed; E-Mail: hywang@kuas.edu.tw; Tel.: +886-7-381-4526 (ext. 5640); Fax: +886-7-381-1182.

Academic Editor: Takayoshi Kobayashi

Received: 9 July 2015 / Accepted: 4 August 2015 / Published: 11 August 2015

\begin{abstract}
A novel systematic approach for synthesizing DDCC-based voltage-mode biquadratic universal filters is proposed. The DDCCs are described by infinity-variables' models of nullor-mirror elements which can be used in the nodal admittance matrix expansion process. Applying the proposed method, the obtained 12 equivalent filters offer the following features: multi-input and two outputs, realization of all five standard filter functions, namely lowpass, bandpass, highpass, notch and allpass, high-input impedance, employing only grounded capacitors and resistors, orthogonal controllability between pole frequency and quality factor, and cascadable, low active and passive sensitivities. The workability of some synthesized filters is verified by HSPICE simulations to demonstrate the feasibility of the proposed method.
\end{abstract}

Keywords: voltage-mode; universal filter; cascadable; NAM; DDCC 


\section{Introduction}

Due to the capability to realize simultaneously multiple filter functions with the same topology, continued researches have focused on the realization of universal filters. The design of biquadratic voltage-mode active filters with high-input impedance has received much interest since they can be directly cascaded to implement higher order filters without the use of additional buffer circuits [1]. Many voltage-mode universal biquadratic filters using current conveyors with multi-input/multi-output were proposed in the literature [2-10].

Recently, a symbolic framework for systematic synthesis of a linear active circuit without any detailed prior knowledge of the circuit form was presented [11-15]. This method, called nodal admittance matrix (NAM) expansion, is very useful to generate various novel circuits in a systematic way. Based on this method, various active networks such as filters, oscillators and gyrators employing OTA, CCII, BOCCII, DVCC and CCCCTA have been synthesized [16-21]. The circuit synthesis procedure proposed in [12] is suitable to synthesize discrete transfer functions with different circuit topologies. It is difficult to synthesize multiple filter functions using an identical topology. The systematic generation of current-mode filters using NAM expansion was reported in [16]. The trans-impedance filter synthesis based on NAM expansion was reported in [17]. In [19], the synthesis of CCII-based voltage-mode high-Q biquadratic notch filter was reported recently.

Since the differential difference current conveyor (DDCC) is a circuit similar to a DDA at the input side and a CCII at the output side [22], it enjoys the combined advantages of the CCII and DDA with high-input impedance, low-output impedance, greater design flexibility, larger signal bandwidth and wider current dynamic range, several universal filters using DDCCs have been proposed [23-26]. Unfortunately, most papers just propose their novel circuits; the design or synthesis methods for DDCC-based universal filters are not available.

In this paper, a systematic generation of cascadable DDCC-based universal voltage-mode biquadratic filters is presented. The obtained 12 filters configurations with two outputs can be used to realize all the five generic filter functions. They comprise three active elements and five passive grounded capacitors and resistors, with the features of high input impedance, low active and passive sensitivities, and orthogonal adjustability of the resonance angular frequency and quality factor. The filter with grounded capacitors is helpful for easing the elimination/accommodation of various parasitic effects for monolithic integration. HSPICE simulations for two illustrated derived filters confirm the workability of the obtained circuits, and hence demonstrate the feasibility of the proposed approach.

\section{Description of the Proposed Method}

The port relations of an ideal DDCC can be characterized by (1), where the plus and minus signs indicate whether the current conveyor is DDCC + or DDCC-. Figure 1 shows the symbolic pathological representations of DDCCs. It is clear that each of terminal- $Y_{i}(i=1-3)$ possesses high input impedance. 


$$
\left[\begin{array}{c}
\mathrm{V}_{\mathrm{X}} \\
\mathrm{I}_{\mathrm{Y} 1} \\
\mathrm{I}_{\mathrm{Y} 2} \\
\mathrm{I}_{\mathrm{Y} 3} \\
\mathrm{I}_{\mathrm{Z}}
\end{array}\right]=\left[\begin{array}{cccc}
1 & -1 & 1 & 0 \\
0 & 0 & 0 & 0 \\
0 & 0 & 0 & 0 \\
0 & 0 & 0 & 0 \\
0 & 0 & 0 & \pm 1
\end{array}\right]\left[\begin{array}{c}
\mathrm{V}_{\mathrm{Y} 1} \\
\mathrm{~V}_{\mathrm{Y} 2} \\
\mathrm{~V}_{\mathrm{Y} 3} \\
\mathrm{I}_{\mathrm{X}}
\end{array}\right]
$$

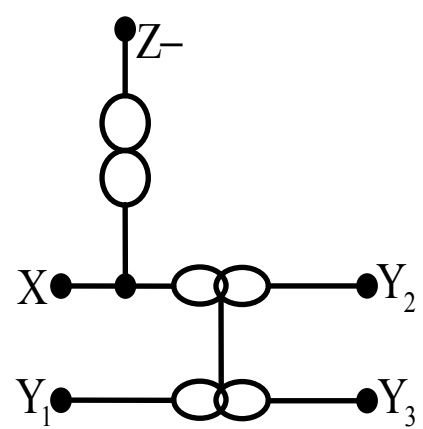

DDCC-

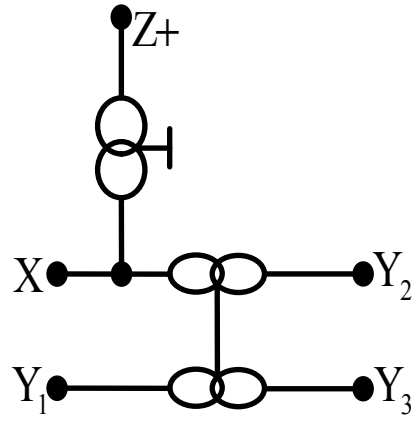

DDCC+

Figure 1. The symbolic pathological representations of DDCCs.

In the NAM expansion process, the addition of row and column of zero terms and infinity-variable terms with a common node on the primary diagonal of the admittance matrix is needed to transform the admittance terms to their correct form. The correct form set of admittance terms includes a unique positive term on the primary diagonal realizing a grounded admittance and a group of four terms with two positive terms on the primary diagonal and two negative terms on the off-diagonal representing a floating admittance. Therefore, in the synthesized circuits, pairs of pathological elements with a common node can be realized by the proper type of CCIIs [19].

The DDCC is similar to a CCII but with two more additional terminals, i.e., terminal- $Y_{2}$ and terminalY3. Thus, the DDCC- and DDCC + can be respectively represented by infinity-variables notation given by Equations (2) and (3) in NAM expansion with the common node on the primary diagonal assigned to terminal-X. The signs of infinity-variables of terminal- $Y_{1}$ and terminal- $Y_{3}$ are different to that of terminal-X, while the signs of infinity-variables of terminal-X and terminal- $Y_{2}$ are identical. Based on the infinity-variables notation in (2) and (3), it can be seen that the connection between terminal-X and terminal- $Y_{1}$ or terminal- $Y_{3}$ corresponds to a nullator, and the connection between terminal-X and terminal-Y $Y_{2}$ corresponds to a voltage-mirror (VM). These relationships are very important for deriving the numerator of the transfer function of the synthesized filters.

$$
\begin{aligned}
& \begin{array}{llll}
Y_{3} & Y_{2} & Y_{1} & X
\end{array} \\
& {\left[\begin{array}{cccc}
\infty_{i} & \infty_{i} & -\infty_{i} & \infty_{i} \\
\infty_{i} & -\infty_{i} & \infty_{i} & -\infty_{i}
\end{array}\right] \begin{array}{l}
X \\
Z-
\end{array}} \\
& \begin{array}{llll}
Y_{3} & Y_{2} & Y_{1} & X
\end{array} \\
& {\left[\begin{array}{cccc}
-\infty_{i} & \infty_{i} & -\infty_{i} & \infty_{i} \\
-\infty_{i} & \infty_{i} & -\infty_{i} & \infty_{i}
\end{array}\right] \mathrm{Z}+}
\end{aligned}
$$


It is known that to synthesize filter circuits using NAM expansion, the denominator $\mathrm{D}(\mathrm{s})$ of a transfer function of a filter should be expressed as an admittance matrix in NAM equations shown in Equation (4). This matrix can be used as a starting matrix to find the circuit configuration with no input signals. Then, the equivalent circuit of an input voltage source as shown in Figure 2 can be injected to the obtained circuit represented by expanded NAM of (4) to obtain the voltage-mode filters [19].

$$
\left[\begin{array}{cccccc}
\mathrm{y}_{1,1} & \mathrm{y}_{1,2} & \ldots & \mathrm{y}_{1, \mathrm{j}} & \ldots & \mathrm{y}_{1, \mathrm{n}} \\
\mathrm{y}_{2,1} & \mathrm{y}_{2,2} & \ldots & \mathrm{y}_{2, \mathrm{j}} & \ldots & \mathrm{y}_{2, \mathrm{n}} \\
\vdots & \vdots & \ldots & \vdots & \ldots & \vdots \\
\mathrm{y}_{\mathrm{i}, 1} & \mathrm{y}_{\mathrm{i}, 2} & \ldots & \mathrm{y}_{\mathrm{i}, \mathrm{j}} & \ldots & \mathrm{y}_{\mathrm{i}, \mathrm{n}} \\
\vdots & \vdots & \ldots & \vdots & \ldots & \vdots \\
\mathrm{y}_{\mathrm{n}, 1} & \mathrm{y}_{\mathrm{n}, 2} & \ldots & \mathrm{y}_{\mathrm{n}, \mathrm{j}} & \ldots & \mathrm{y}_{\mathrm{n}, \mathrm{n}}
\end{array}\right]
$$

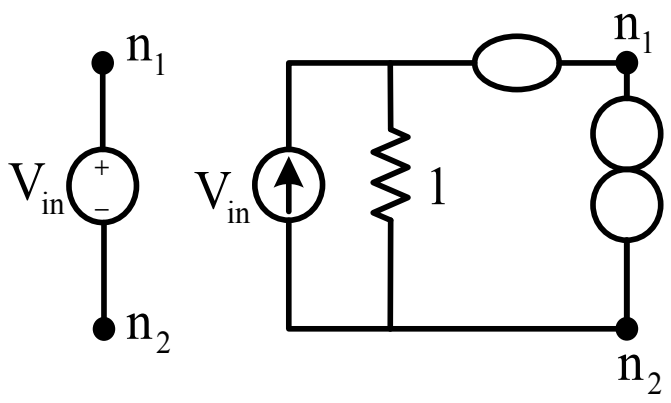

Figure 2. R-nullor equivalent circuit of a voltage source.

To synthesize DDCC-grounded capacitor-based filters using NAM expansion, we firstly use the NAM stamps of CCIIs [15] to expand the starting matrix in (4). The expanded NAM of (4) includes the correct form of admittance elements and pairs of infinity-variables represented terminal-X, terminal-Z and one terminal-Yi of DDCCs. The remained $Y_{i}$-terminals can be used to inject the input voltage source for deriving high input impedance filters. The procedure can be summarized as follows.

Step 1: Of the desired transfer function of the synthesized filter in the form of the Matrix (4). It must be noted that each capacitor in the denominator must be arranged to have only a single position on the primary diagonal to obtain circuits with grounded capacitors.

Step 2: Introduce a row and a column of zeros to row 1 and column 1 and place a unity resistor to position (1,1) of (4). The existing columns and rows are moved to the right and to the bottom, as given by (5). Then add infinity variables and zero terms to realize a nullator between column 1 and column 2 and a norator between row 2 and ground. The Step 2 corresponds to the adding of the equivalent circuit of voltage source in Figure 2 [19]. So, Matrix (5) becomes (6). 


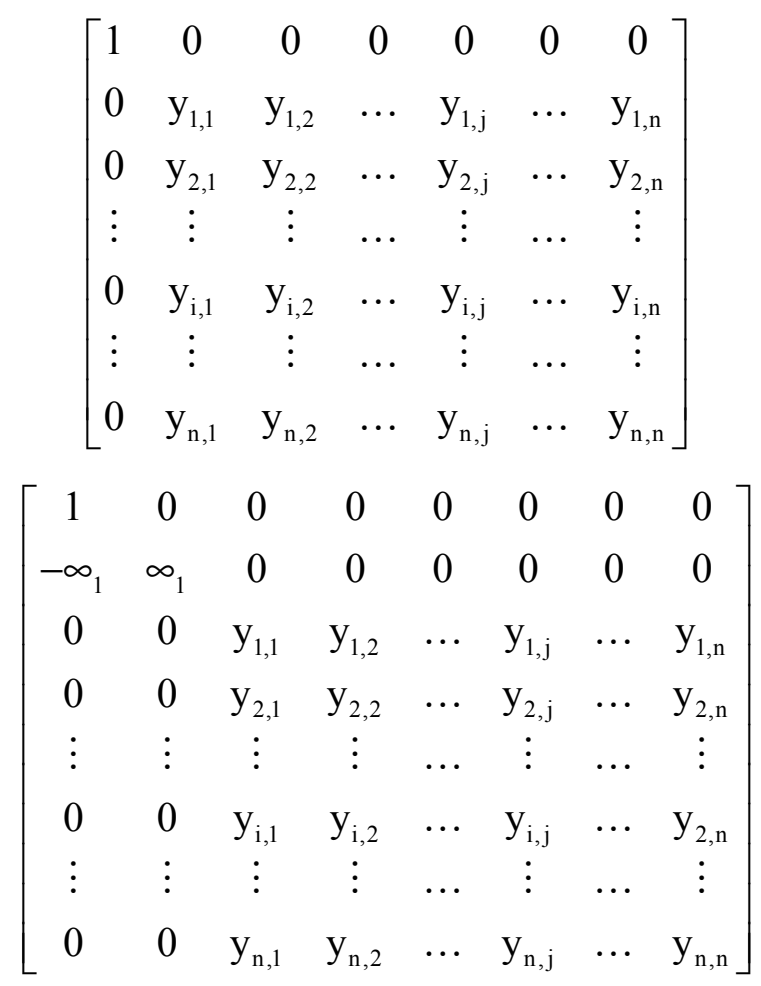

Step 3: Use the NAM expansion method to expand the Matrix (6) $[12,15]$. The obtained matrix can be expressed by (7), for example.

$$
\left[\begin{array}{ccccccccc}
1 & 0 & 0 & 0 & 0 & 0 & 0 & 0 & 0 \\
-\infty_{1} & \infty_{1} & 0 & 0 & 0 & 0 & 0 & 0 & 0 \\
0 & 0 & y_{1,1} & \infty_{i} & \ldots & y_{1, j} & \cdots & y_{1, n} & -\infty_{i} \\
0 & 0 & y_{2,1} & y_{2,2} & \cdots & y_{2, j} & \cdots & y_{2, n} & 0 \\
\vdots & \vdots & \vdots & \vdots & \ldots & \vdots & \cdots & \vdots & \vdots \\
0 & 0 & y_{i, 1} & y_{i, 2} & \cdots & y_{i, j} & \cdots & y_{i, n} & 0 \\
\vdots & \vdots & \vdots & \vdots & \cdots & \vdots & \cdots & \vdots & \vdots \\
0 & 0 & y_{n, 1} & y_{n, 2} & \cdots & y_{n, j} & \cdots & y_{n, n} & 0 \\
0 & 0 & 0 & -\infty_{i} & 0 & 0 & 0 & 0 & y_{1,2}+\infty_{i}
\end{array}\right]
$$

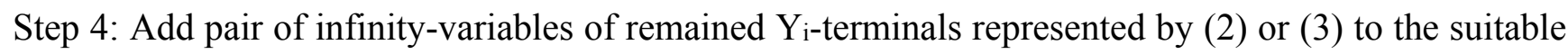
positions in column 2 of the Matrix (7) to realize the infinity-variables notation of a DDCC+ or DDCC-. This operation will duplicate the existing admittance terms to the first column of (5), so the numerator of the desired transfer function is obtained. For example, by adding a pair of $\pm \infty_{i}$ to the second column of (7), the term $\mathrm{y}_{1,2}$ will be duplicated in the first column of (5) to obtain the desired numerator, as shown in (8). The addition of infinity-variable pairs to column 2 corresponds to applying input voltage signal to the added $\mathrm{Y}_{\mathrm{i}}$-terminals at node 2 . This operation will not affect the denominator of the transfer function. The obtained matrix represents the full matrix of the synthesized circuit. 


$$
\left[\begin{array}{ccccccccc}
1 & 0 & 0 & 0 & 0 & 0 & 0 & 0 & 0 \\
-\infty_{1} & \infty_{1} & 0 & 0 & 0 & 0 & 0 & 0 & 0 \\
0 & \pm \infty_{i} & y_{1,1} & \infty_{i} & \ldots & y_{1, j} & \ldots & y_{1, n} & -\infty_{i} \\
0 & 0 & y_{2,1} & y_{2,2} & \ldots & y_{2, j} & \ldots & y_{2, n} & 0 \\
\vdots & \vdots & \vdots & \vdots & \ldots & \vdots & \ldots & \vdots & \vdots \\
0 & 0 & y_{i, 1} & y_{i, 2} & \ldots & y_{i, j} & \ldots & y_{i, n} & 0 \\
\vdots & \vdots & \vdots & \vdots & \ldots & \vdots & \ldots & \vdots & \vdots \\
0 & 0 & y_{n, 1} & y_{n, 2} & \ldots & y_{n, j} & \ldots & y_{n, n} & 0 \\
0 & \pm \infty_{i} & 0 & -\infty_{i} & 0 & 0 & 0 & 0 & y_{1,2}+\infty_{i}
\end{array}\right]
$$

It can be observed that in the starting Matrix (5), the node 1 is chosen as input voltage node and other nodes can be output nodes. In (6), the node 1 and node 2 are connected by a nullator then they are equivalent to the input node, and other nodes can be output nodes. In Step 4, each pair of infinity-variables added to the second column of the obtained matrix in Step 3 corresponds to the injecting of input voltage signal to one Y-terminal of DDCCs. So, the circuits with high input impedance and multi-input and multi-output properties can therefore be synthesized.

\section{Application Examples}

We hope to synthesize biquadratic voltage-mode universal filters using a minimum number of passive elements with independent adjustable parameters of $\mathrm{Q}$ factor and pole frequency. The denominator of the transfer function is chosen as (9).

$$
\mathrm{D}(\mathrm{s})=\mathrm{s}^{2} \mathrm{C}_{1} \mathrm{C}_{2}+\mathrm{sC}_{2} \mathrm{G}_{1}+\mathrm{G}_{2} \mathrm{G}_{3}
$$

According to the procedure of Step 1 in Section 2, the Equation (9) is expressed by (10) and (11) in the form of (4).

$$
\begin{array}{r}
{\left[\begin{array}{cc}
\mathrm{G}_{1}+\mathrm{sC}_{1} & -\mathrm{G}_{2} \\
\mathrm{G}_{3} & \mathrm{sC}_{2}
\end{array}\right]} \\
{\left[\begin{array}{cc}
\mathrm{G}_{1}+\mathrm{sC}_{1} & \mathrm{G}_{2} \\
-\mathrm{G}_{3} & \mathrm{sC}_{2}
\end{array}\right]}
\end{array}
$$

The Matrices (10) and (11) are defined as NAM type-A and NAM type-B, respectively. They are used as the starting matrices in NAM expansion.

\subsection{Synthesis of Type-A Universal Filters}

Following Step 2 of the procedure in Section 2, the equivalent NAMs (12) and (13) are obtained from (10). In the Matrix (12), the node 1 is chosen as input node, nodes 2 and 3 are chosen as outputs, respectively denoted by $V_{\text {ou1 }}$ and $V_{\text {out2. }}$. In (13), the output voltage nodes $V_{\text {out1 }}$ and $V_{\text {out2 }}$ are moved to node 3 and 4, respectively. 


$$
\begin{gathered}
{\left[\begin{array}{ccc}
1 & 0 & 0 \\
0 & \mathrm{G}_{1}+\mathrm{sC}_{1} & -\mathrm{G}_{2} \\
0 & \mathrm{G}_{3} & \mathrm{sC}_{2}
\end{array}\right]} \\
{\left[\begin{array}{cccc}
1 & 0 & 0 & 0 \\
-\infty_{1} & \infty_{1} & 0 & 0 \\
0 & 0 & \mathrm{G}_{1}+\mathrm{sC}_{1} & -\mathrm{G}_{2} \\
0 & 0 & \mathrm{G}_{3} & \mathrm{sC}_{2}
\end{array}\right]}
\end{gathered}
$$

Using Step 3, three columns and rows of zero terms are added and pairs of nullor-mirror elements represented by $\infty_{2}, \infty_{3}$ and $\infty_{4}$ are introduced to the right and bottom of Matrix (13). So, Matrix (13) can be expanded as (14). There are eight alternative cases (cases 1-8) in expanding the Matrix (13), as shown in Table 1.

$$
\left[\begin{array}{ccccccc}
1 & 0 & 0 & 0 & 0 & 0 & 0 \\
-\infty_{1} & \infty_{1} & 0 & 0 & 0 & 0 & 0 \\
0 & 0 & \mathrm{G}_{1}+\infty_{2} & -\infty_{3} & -\infty_{2} & \infty_{3} & 0 \\
0 & 0 & \infty_{4} & \mathrm{sC}_{2} & 0 & 0 & -\infty_{4} \\
0 & 0 & -\infty_{2} & 0 & \mathrm{sC}_{1}+\infty_{2} & 0 & 0 \\
0 & 0 & 0 & -\infty_{3} & 0 & \mathrm{G}_{2}+\infty_{3} & 0 \\
0 & 0 & -\infty_{4} & 0 & 0 & 0 & \mathrm{G}_{3}+\infty_{4}
\end{array}\right]
$$

In (14), the $\operatorname{DDCC}(1), \operatorname{DDCC}(2)$ and $\operatorname{DDCC}(3)$ are represented by terms $\pm \infty_{2}, \pm \infty 3$ and $\pm \infty_{4}$, respectively. Based on the NAM stamps in (2) and (3) and the common node on the primary diagonal assigned for terminal-X of a DDCC, the terminal-X of DDCC(1) can be node 5, terminal-Y $Y_{1}$ and terminal-Z (of minus-type DDCC) are connected to node 3. For the $\operatorname{DDCC}(2)$, the terminal-X is connected to node 6 , terminal- $Y_{1}$ is connected to node 4 and terminal-Z (plus-type DDCC) is connected to node 3. For the $\operatorname{DDCC}(3)$, the terminal-X is connected to node 7 , terminal- $Y_{1}$ is connected to node 3 and terminal-Z (minus type DDCC) is connected to node 4 . All of the terminal- $Y_{2}$ and terminal-Y $Y_{3}$ of $\operatorname{DDCC}(1), \operatorname{DDCC}(2)$ and $\operatorname{DDCC}(3)$ can be used to inject the input voltage source.

Using Step 4, by injecting the input voltage source into terminal- $Y_{2}$ of DDCC(1), the term $-\mathrm{SC}_{1}$ will be added to position $(2,1)$ of $(12)$, then a highpass function at $\mathrm{V}_{\text {out1 }}$ and bandpass function at $\mathrm{V}_{\text {out2 }}$ can be obtained. This operation corresponds to the inserting of term $\pm \infty_{2}$ to the second column of (14), as shown in (15). The obtained filter represented by (15) is shown in Figure $3 a$ with nodes $V_{\text {in2}}, V_{\text {in3 }}, V_{\text {in4, }}$, $\mathrm{V}_{\text {in5 }}$ and $\mathrm{V}_{\text {in6 }}$ being grounded.

By applying the input voltage source to terminal- $\mathrm{Y}_{3}$ of $\mathrm{DDCC}(1)$, the term $\mathrm{sC}_{1}$ will be also created in position (2,1) of (12). Therefore, the admittance matrix is shown in (16) and the obtained transfer functions at nodes $V_{\text {out1 }}$ and $V_{\text {out2 }}$ are identical to that obtained in (15) but with reverse signs. The derived circuit is shown in Figure $3 a$ with moving the injected voltage source equivalent circuit to node $\mathrm{V}_{\text {in2 }}$ and grounding nodes $\mathrm{V}_{\text {in1 }}, \mathrm{V}_{\text {in } 3}, \mathrm{~V}_{\text {in } 4}, \mathrm{~V}_{\text {in5 }}$ and $\mathrm{V}_{\text {in6. }}$ 
Table 1. Eight cases of expanding NAM Type-A.

\begin{tabular}{|c|c|c|c|c|c|c|c|c|c|c|c|c|c|}
\hline \multicolumn{7}{|c|}{ NAM Type-A (Case 1) } & \multicolumn{7}{|c|}{ NAM Type-A (Case 2) } \\
\hline 1 & 0 & 0 & 0 & 0 & 0 & 0 & 1 & 0 & 0 & 0 & 0 & 0 & 0 \\
\hline$-\infty_{1}$ & $\infty_{1}$ & 0 & 0 & 0 & 0 & 0 & $-\infty_{1}$ & $\infty_{1}$ & 0 & 0 & 0 & 0 & 0 \\
\hline 0 & 0 & $\mathrm{G}_{1}+\infty$ & $-\infty_{3}$ & $-\infty_{2}$ & $\infty_{3}$ & 0 & 0 & 0 & $\mathrm{G}_{1}+\infty_{2}$ & $-\infty_{3}$ & $-\infty_{2}$ & $\infty_{3}$ & 0 \\
\hline 0 & 0 & $\infty_{4}$ & $\mathrm{sC}_{2}$ & 0 & 0 & $-\infty_{4}$ & 0 & 0 & $\infty_{4}$ & $\mathrm{sC}_{2}$ & 0 & 0 & $\infty_{4}$ \\
\hline 0 & 0 & $-\infty_{2}$ & 0 & $\mathrm{sC}_{1}+\infty_{2}$ & 0 & 0 & 0 & 0 & $-\infty_{2}$ & 0 & $\mathrm{sC}_{1}+\infty_{2}$ & 0 & 0 \\
\hline 0 & 0 & 0 & $-\infty_{3}$ & 0 & $\mathrm{G}_{2}+\infty_{3}$ & 0 & 0 & 0 & 0 & $-\infty_{3}$ & 0 & $\mathrm{G}_{2}+\infty_{3}$ & 0 \\
\hline 0 & 0 & $-\infty_{4}$ & 0 & 0 & 0 & $\left.\mathrm{G}_{3}+\infty_{4}\right]$ & 0 & 0 & $\infty_{4}$ & 0 & 0 & 0 & $\mathrm{G}_{3}+\infty_{4}$ \\
\hline \multicolumn{7}{|c|}{ NAM Type-A (Case 3) } & \multicolumn{7}{|c|}{ NAM Type-A (Case 4) } \\
\hline 1 & 0 & 0 & 0 & 0 & 0 & 0 & 1 & 0 & 0 & 0 & 0 & 0 & 0 \\
\hline$-\infty$ & $\infty_{1}$ & 0 & 0 & 0 & 0 & 0 & $-\infty_{1}$ & $\infty_{1}$ & 0 & 0 & 0 & 0 & 0 \\
\hline 0 & 0 & $\mathrm{G}_{1}+\infty_{2}$ & $-\infty_{3}$ & $-\infty_{2}$ & $-\infty_{3}$ & 0 & 0 & 0 & $\mathrm{G}_{1}+\infty_{2}$ & $-\infty_{3}$ & $-\infty_{2}$ & $-\infty_{3}$ & 0 \\
\hline 0 & 0 & $\infty_{4}$ & $\mathrm{sC}_{2}$ & 0 & 0 & $-\infty_{4}$ & 0 & 0 & $\infty_{4}$ & $\mathrm{sC}_{2}$ & 0 & 0 & $\infty_{4}$ \\
\hline 0 & 0 & $-\infty_{2}$ & 0 & $\mathrm{sC}_{1}+\infty$ & 0 & 0 & 0 & 0 & $-\infty_{2}$ & 0 & $\mathrm{sC}_{1}+\infty_{2}$ & 0 & 0 \\
\hline 0 & 0 & 0 & $\infty_{3}$ & 0 & $\mathrm{G}_{2}+\infty_{3}$ & 0 & 0 & 0 & 0 & $\infty_{3}$ & 0 & $\mathrm{G}_{2}+\infty_{3}$ & 0 \\
\hline 0 & 0 & $-\infty_{4}$ & 0 & 0 & 0 & $\left.\mathrm{G}_{3}+\infty_{4}\right\rfloor$ & 0 & 0 & $\infty_{4}$ & 0 & 0 & 0 & $\mathrm{G}_{3}+\infty_{4}$ \\
\hline \multicolumn{7}{|c|}{ NAM Type-A (Case 5) } & \multicolumn{7}{|c|}{ NAM Type-A (Case 6) } \\
\hline 1 & 0 & 0 & 0 & 0 & 0 & 0 & 1 & 0 & 0 & 0 & 0 & 0 & 0 \\
\hline$-\infty$ & $\infty_{1}$ & 0 & 0 & 0 & 0 & 0 & $-\infty$ & $\infty_{1}$ & 0 & 0 & 0 & 0 & 0 \\
\hline 0 & 0 & $\mathrm{G}_{1}+\infty_{2}$ & $-\infty_{3}$ & $\infty_{2}$ & $\infty_{3}$ & 0 & 0 & 0 & $\mathrm{G}_{1}+\infty_{2}$ & $-\infty_{3}$ & $\infty_{2}$ & $\infty_{3}$ & 0 \\
\hline 0 & 0 & $\infty_{4}$ & $\mathrm{sC}_{2}$ & 0 & 0 & $-\infty_{4}$ & 0 & 0 & $\infty_{4}$ & $\mathrm{sC}_{2}$ & 0 & 0 & $\infty_{4}$ \\
\hline 0 & 0 & $\infty_{2}$ & 0 & $\mathrm{sC}_{1}+\infty$ & 0 & 0 & 0 & 0 & $\infty_{2}$ & 0 & $\mathrm{sC}_{1}+\infty$ & 0 & 0 \\
\hline 0 & 0 & 0 & $-\infty_{3}$ & 0 & $\mathrm{G}_{2}+\infty_{3}$ & 0 & 0 & 0 & 0 & $-\infty_{3}$ & 0 & $\mathrm{G}_{2}+\infty_{3}$ & 0 \\
\hline 0 & 0 & $-\infty_{4}$ & 0 & 0 & 0 & $\left.\mathrm{G}_{3}+\infty_{4}\right\rfloor$ & 0 & 0 & $\infty_{4}$ & 0 & 0 & 0 & $\mathrm{G}_{3}+\infty_{4}$ \\
\hline \multicolumn{7}{|c|}{ NAM Type-A (Case 7) } & \multicolumn{7}{|c|}{ NAM Type-A (Case 8) } \\
\hline 1 & 0 & 0 & 0 & 0 & 0 & 0 & 1 & 0 & 0 & 0 & 0 & 0 & 0 \\
\hline$-\infty$ & $\infty_{1}$ & 0 & 0 & 0 & 0 & 0 & $-\infty$ & $\infty_{1}$ & 0 & 0 & 0 & 0 & 0 \\
\hline 0 & 0 & $\mathrm{G}_{1}+\infty_{2}$ & $-\infty_{3}$ & $\infty_{2}$ & $-\infty_{3}$ & 0 & 0 & 0 & $\mathrm{G}_{1}+\infty_{2}$ & $-\infty_{3}$ & $\infty_{2}$ & $-\infty_{3}$ & 0 \\
\hline 0 & 0 & $\infty_{4}$ & $\mathrm{sC}_{2}$ & 0 & 0 & $-\infty_{4}$ & 0 & 0 & $\infty_{4}$ & $\mathrm{sC}_{2}$ & 0 & 0 & $\infty_{4}$ \\
\hline 0 & 0 & $\infty_{2}$ & 0 & $\mathrm{sC}_{1}+\infty_{2}$ & 0 & 0 & 0 & 0 & $\infty_{2}$ & 0 & $\mathrm{sC}_{1}+\infty$ & 0 & 0 \\
\hline 0 & 0 & 0 & $\infty_{3}$ & 0 & $\mathrm{G}_{2}+\infty_{3}$ & 0 & 0 & 0 & 0 & $\infty_{3}$ & 0 & $\mathrm{G}_{2}+\infty_{3}$ & 0 \\
\hline 0 & 0 & $-\infty_{4}$ & 0 & 0 & 0 & $\mathrm{G}_{3}+\infty_{4}$ & 0 & 0 & $\infty_{4}$ & 0 & 0 & 0 & $\mathrm{G}_{3}+\infty_{4}$ \\
\hline
\end{tabular}

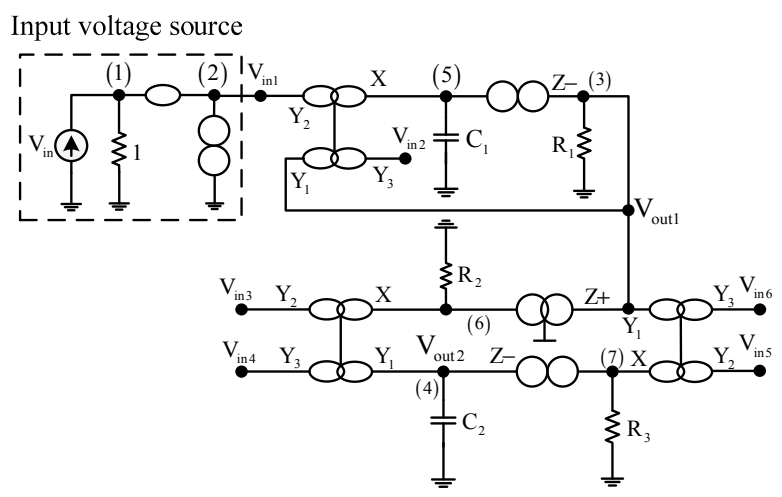

a)

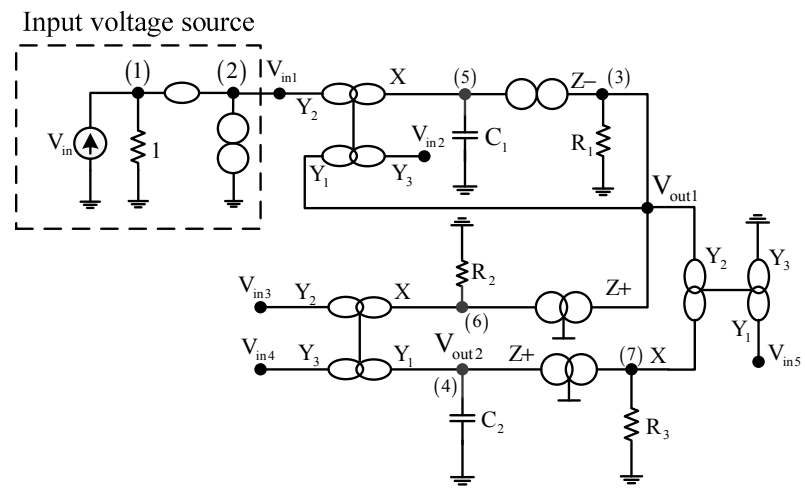

b)

Figure 3. Cont. 


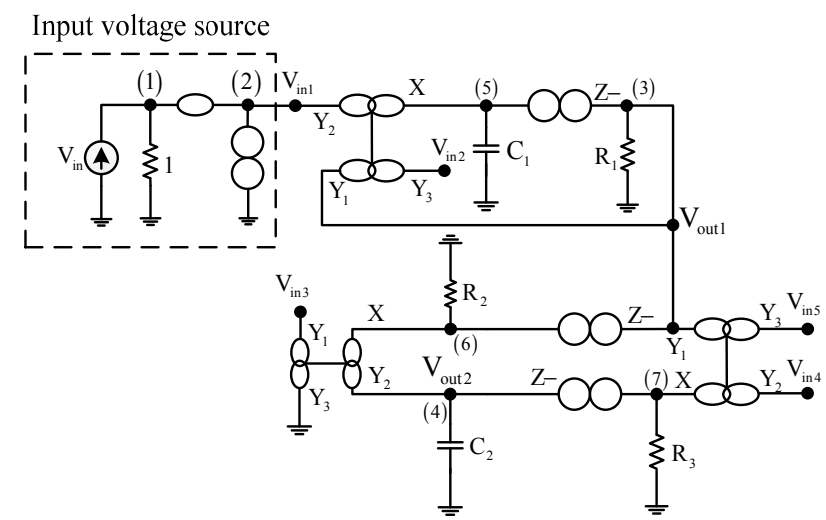

c)

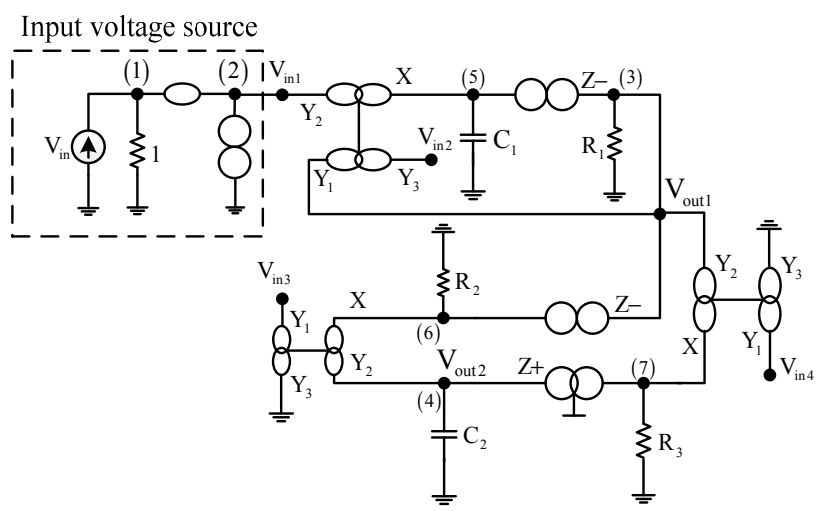

d)

Figure 3. The pathological representations of derived type-A filters (cases 1-4).

$$
\begin{aligned}
& {\left[\begin{array}{ccccccc}
1 & 0 & 0 & 0 & 0 & 0 & 0 \\
-\infty_{1} & \infty_{1} & 0 & 0 & 0 & 0 & 0 \\
0 & -\infty_{2} & \mathrm{G}_{1}+\infty_{2} & -\infty_{3} & -\infty_{2} & \infty_{3} & 0 \\
0 & 0 & \infty_{4} & \mathrm{sC}_{2} & 0 & 0 & -\infty_{4} \\
0 & \infty_{2} & -\infty_{2} & 0 & \mathrm{sC}_{1}+\infty_{2} & 0 & 0 \\
0 & 0 & 0 & -\infty_{3} & 0 & \mathrm{G}_{2}+\infty_{3} & 0 \\
0 & 0 & -\infty_{4} & 0 & 0 & 0 & \mathrm{G}_{3}+\infty_{4}
\end{array}\right]} \\
& {\left[\begin{array}{ccccccc}
1 & 0 & 0 & 0 & 0 & 0 & 0 \\
-\infty & \infty_{1} & 0 & 0 & 0 & 0 & 0 \\
0 & \infty_{2} & \mathrm{G}_{1}+\infty_{2} & -\infty_{3} & -\infty_{2} & \infty_{3} & 0 \\
0 & 0 & \infty_{4} & \mathrm{sC}_{2} & 0 & 0 & -\infty_{4} \\
0 & -\infty_{2} & -\infty_{2} & 0 & \mathrm{sC}_{1}+\infty_{2} & 0 & 0 \\
0 & 0 & 0 & -\infty_{3} & 0 & \mathrm{G}_{2}+\infty_{3} & 0 \\
0 & 0 & -\infty_{4} & 0 & 0 & 0 & \mathrm{G}_{3}+\infty_{4}
\end{array}\right]}
\end{aligned}
$$

Similarly, by applying the input voltage source to terminal-Y 2 of $\operatorname{DDCC}(2)$, term $\mathrm{G}_{2}$ will appear in the position $(2,1)$ of (12), then a bandpass function at $\mathrm{V}_{\text {out1 }}$ and a lowpass function at $\mathrm{V}_{\text {out2 }}$ can be obtained. The admittance matrix can be given in (17) and the derived circuit is shown in Figure 3a with moving the injected voltage source to node $V_{\text {in3 }}$ and grounding nodes $V_{\text {in1}}, V_{\text {in2}}, V_{\text {in4 }}, V_{\text {in5 }}$ and $V_{\text {in6. }}$

$$
\left[\begin{array}{ccccccc}
1 & 0 & 0 & 0 & 0 & 0 & 0 \\
-\infty_{1} & \infty_{1} & 0 & 0 & 0 & 0 & 0 \\
0 & \infty_{3} & \mathrm{G}_{1}+\infty_{2} & -\infty_{3} & -\infty_{2} & \infty_{3} & 0 \\
0 & 0 & \infty_{4} & \mathrm{sC}_{2} & 0 & 0 & -\infty_{4} \\
0 & 0 & -\infty_{2} & 0 & \mathrm{sC}_{1}+\infty_{2} & 0 & 0 \\
0 & \infty_{3} & 0 & -\infty_{3} & 0 & \mathrm{G}_{2}+\infty_{3} & 0 \\
0 & 0 & -\infty_{4} & 0 & 0 & 0 & \mathrm{G}_{3}+\infty_{4}
\end{array}\right]
$$

By applying the input voltage source to terminal- $\mathrm{Y}_{3}$ of $\mathrm{DDCC}(2)$, the term $-\mathrm{G}_{2}$ will appear in position $(2,1)$ of $(12)$, then we can obtain the admittance matrix in (18) and the filter with identical 


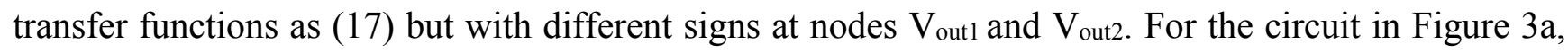
moving the injected voltage source equivalent circuit to node $V_{\text {in }}$ with nodes $V_{\text {in1 }}, V_{\text {in2}}, V_{\text {in3 }}, V_{\text {ins }}$ and $\mathrm{V}_{\text {in6 }}$ as grounded nodes, we can obtain the filter represented by (18).

$$
\left[\begin{array}{ccccccc}
1 & 0 & 0 & 0 & 0 & 0 & 0 \\
-\infty_{1} & \infty_{1} & 0 & 0 & 0 & 0 & 0 \\
0 & -\infty_{3} & \mathrm{G}_{1}+\infty_{2} & -\infty_{3} & -\infty_{2} & \infty_{3} & 0 \\
0 & 0 & \infty_{4} & \mathrm{sC}_{2} & 0 & 0 & -\infty_{4} \\
0 & 0 & -\infty_{2} & 0 & \mathrm{sC}_{1}+\infty_{2} & 0 & 0 \\
0 & -\infty_{3} & 0 & -\infty_{3} & 0 & \mathrm{G}_{2}+\infty_{3} & 0 \\
0 & 0 & -\infty_{4} & 0 & 0 & 0 & \mathrm{G}_{3}+\infty_{4}
\end{array}\right]
$$

Also, a lowpass function at $\mathrm{V}_{\text {outl }}$ can be achieved by applying the input voltage source to terminal- $\mathrm{Y}_{2}$ of DDCC(3) when the term $-\mathrm{G}_{3}$ appear in position $(3,1)$ of $(12)$. This operation corresponds to the inserting of terms $\pm \infty_{4}$ to the second column of (14), as shown in (19). The obtained circuit is shown in Figure 3 a by moving the injected voltage source to node $V_{\text {in } 5}$ with nodes $V_{\text {in1 }}, V_{\text {in2, }} V_{\text {in3 }}, V_{\text {in4 }}$ and $V_{\text {in6 }}$ being grounded.

$$
\left[\begin{array}{ccccccc}
1 & 0 & 0 & 0 & 0 & 0 & 0 \\
-\infty_{1} & \infty_{1} & 0 & 0 & 0 & 0 & 0 \\
0 & 0 & \mathrm{G}_{1}+\infty_{2} & -\infty_{3} & -\infty_{2} & \infty_{3} & 0 \\
0 & -\infty_{4} & \infty_{4} & \mathrm{sC}_{2} & 0 & 0 & -\infty_{4} \\
0 & 0 & -\infty_{2} & 0 & \mathrm{sC}_{1}+\infty_{2} & 0 & 0 \\
0 & 0 & 0 & -\infty_{3} & 0 & \mathrm{G}_{2}+\infty_{3} & 0 \\
0 & \infty_{4} & -\infty_{4} & 0 & 0 & 0 & \mathrm{G}_{3}+\infty_{4}
\end{array}\right]
$$

By applying the input voltage source to terminal- $Y_{3}$ of $\operatorname{DDCC}(3)$, term $\mathrm{G}_{3}$ will arise in position $(3,1)$ of (12), then the obtained transfer function at node $V_{\text {out }}$ is identical to the circuit represented by (19) with reverse sign. Its admittance matrix is shown in (20) and the circuit is given in Figure 3a by moving the injected voltage source to node $V_{\text {in6 }}$ with nodes $V_{\text {in1 }}, V_{\text {in2 } 2, ~} V_{\text {in3 }}, V_{\text {in } 4}$ and $V_{\text {in5 }}$ being grounded.

$$
\left[\begin{array}{ccccccc}
1 & 0 & 0 & 0 & 0 & 0 & 0 \\
-\infty_{1} & \infty_{1} & 0 & 0 & 0 & 0 & 0 \\
0 & 0 & \mathrm{G}_{1}+\infty_{2} & -\infty_{3} & -\infty_{2} & \infty_{3} & 0 \\
0 & \infty_{4} & \infty_{4} & \mathrm{sC}_{2} & 0 & 0 & -\infty_{4} \\
0 & 0 & -\infty_{2} & 0 & \mathrm{sC}_{1}+\infty_{2} & 0 & 0 \\
0 & 0 & 0 & -\infty_{3} & 0 & \mathrm{G}_{2}+\infty_{3} & 0 \\
0 & -\infty_{4} & -\infty_{4} & 0 & 0 & 0 & \mathrm{G}_{3}+\infty_{4}
\end{array}\right]
$$

In addition, a notch function at $\mathrm{V}_{\text {out }}$ can be achieved by applying the input voltage source to terminal- $\mathrm{Y}_{2}$ of DDCC(1) and terminal- $\mathrm{Y}_{2}$ of $\mathrm{DDCC}(3)$ when the terms $-\mathrm{SC}_{1}$ and $-\mathrm{G}_{3}$ arise in positions $(2,1)$ and $(3,1)$ of $(12)$, respectively. This operation corresponds to the inserting of terms $\pm \infty 2$ and $\pm \infty 4$ to the second column of (14), as shown in (21). The obtained circuit is given in Figure 3a by moving the injected voltage source to the merged node of $V_{\text {in1 }}$ and $V_{\text {in } 5}$ with nodes $V_{\text {in2}}, V_{\text {in3 }}, V_{\text {in } 4}$ and $V_{\text {in6 }}$ being 
grounded. Another notch function at $\mathrm{V}_{\text {out1 }}$ can be also obtained by injecting the input voltage source to the merged node of $V_{\text {in2 }}$ and $V_{\text {in } 6}$ in Figure $3 a$ with nodes $V_{\text {in1 }}, V_{\text {in3 }}, V_{\text {in } 4}$ and $V_{\text {in }}$ being grounded.

$$
\left[\begin{array}{ccccccc}
1 & 0 & 0 & 0 & 0 & 0 & 0 \\
-\infty_{1} & \infty_{1} & 0 & 0 & 0 & 0 & 0 \\
0 & -\infty_{2} & \mathrm{G}_{1}+\infty_{2} & -\infty_{3} & -\infty_{2} & \infty_{3} & 0 \\
0 & -\infty_{4} & \infty_{4} & \mathrm{sC}_{2} & 0 & 0 & -\infty_{4} \\
0 & \infty_{2} & -\infty_{2} & 0 & \mathrm{sC}_{1}+\infty_{2} & 0 & 0 \\
0 & 0 & 0 & -\infty_{3} & 0 & \mathrm{G}_{2}+\infty_{3} & 0 \\
0 & \infty_{4} & -\infty_{4} & 0 & 0 & 0 & \mathrm{G}_{3}+\infty_{4}
\end{array}\right]
$$

Applying the input voltage source to terminal- $Y_{2}$ of DDCC(1), terminal- $Y_{2}$ of DDCC(2) and terminal- $\mathrm{Y}_{2}$ of $\operatorname{DDCC}(3)$, terms $-\mathrm{sC}_{1}+\mathrm{G}_{2}$ and $-\mathrm{G}_{3}$ will be created in positions $(2,1)$ and $(3,1)$ of $(12)$, respectively, then an allpass function at $V_{\text {outl }}$ (with $\mathrm{G}_{2}=\mathrm{G}_{1}$ ) can be achieved. This operation corresponds to the insertion of the terms $\pm \infty_{2}, \infty_{3}$ and $\pm \infty_{4}$ to the second column of (14) as shown in (22). In Figure $3 \mathrm{a}$, moving the injected voltage source to the merged node of $\mathrm{V}_{\text {in1 }}, \mathrm{V}_{\text {in } 3}$ and $\mathrm{V}_{\text {ins }}$ with nodes $\mathrm{V}_{\text {in2}}, \mathrm{V}_{\text {in } 4}$ and $\mathrm{V}_{\text {in6 }}$ being grounded, we can obtain the filter represented by (22). Another allpass function at $\mathrm{V}_{\text {out1 }}$ can be also obtained by injecting the input voltage source to the merged node of $\mathrm{V}_{\text {in2, }}$, $V_{\text {in } 4}$ and $V_{\text {in6 }}$ in Figure 3 a with nodes $V_{\text {in1 }}, V_{\text {in3 } 3 \text {, and }} V_{\text {ins }}$ being grounded.

$$
\left[\begin{array}{ccccccc}
1 & 0 & 0 & 0 & 0 & 0 & 0 \\
-\infty_{1} & \infty_{1} & 0 & 0 & 0 & 0 & 0 \\
0 & -\infty_{2}+\infty_{3} & \mathrm{G}_{1}+\infty_{2} & -\infty_{3} & -\infty_{2} & \infty_{3} & 0 \\
0 & -\infty_{4} & \infty_{4} & \mathrm{sC}_{2} & 0 & 0 & -\infty_{4} \\
0 & \infty_{2} & -\infty_{2} & 0 & \mathrm{sC}_{1}+\infty_{2} & 0 & 0 \\
0 & \infty_{3} & 0 & -\infty_{3} & 0 & \mathrm{G}_{2}+\infty_{3} & 0 \\
0 & \infty_{4} & -\infty_{4} & 0 & 0 & 0 & \mathrm{G}_{3}+\infty_{4}
\end{array}\right]
$$

In the same way, the synthesized procedure can be applied to the matrices for cases 2-8 in Table 1 . Four equivalent circuits of the derived filters for cases $1-4$ of derived type-A filters in Table 1 are shown in Figure 3. The output transfer functions of the synthesized circuits for case 1 are given by (23) and (24). Besides, four equivalent circuits of the synthesized filters for cases 5-8 of derived type-A filters in Table 1 are shown in Figure 4. The output transfer functions of the synthesized circuits for case 5 are given by (25) and (26). Figure $5 \mathrm{a}-\mathrm{d}$ and $\mathrm{e}-\mathrm{h}$ show the practical configurations for the pathological equivalents in Figures 3 and 4, respectively.

$$
\begin{aligned}
& \mathrm{V}_{\text {out } 1}= \frac{\mathrm{s}^{2} \mathrm{C}_{1} \mathrm{C}_{2} \mathrm{~V}_{\text {in } 1}-\mathrm{s}^{2} \mathrm{C}_{1} \mathrm{C}_{2} \mathrm{~V}_{\text {in } 2}-\mathrm{sC}_{2} \mathrm{G}_{2} \mathrm{~V}_{\text {in } 3}+\mathrm{sC}_{2} \mathrm{G}_{2} \mathrm{~V}_{\text {in } 4}+\mathrm{G}_{2} \mathrm{G}_{3} \mathrm{~V}_{\text {in } 5}-\mathrm{G}_{2} \mathrm{G}_{3} \mathrm{~V}_{\text {in } 6}}{\mathrm{~s}^{2} \mathrm{C}_{1} \mathrm{C}_{2}+\mathrm{sC}_{2} \mathrm{G}_{1}+\mathrm{G}_{2} \mathrm{G}_{3}} \\
& \mathrm{~V}_{\text {out } 2}=\frac{-\mathrm{sC}_{1} \mathrm{G}_{3} \mathrm{~V}_{\text {in } 1}+\mathrm{sC}_{1} \mathrm{G}_{3} \mathrm{~V}_{\text {in } 2}+\mathrm{G}_{2} \mathrm{G}_{3} \mathrm{~V}_{\text {in } 3}-\mathrm{G}_{2} \mathrm{G}_{3} \mathrm{~V}_{\text {in } 4}+\mathrm{G}_{3}\left(\mathrm{G}_{1}+\mathrm{s} \mathrm{C}_{1}\right) \mathrm{V}_{\text {in } 5}-\mathrm{G}_{3}\left(\mathrm{G}_{1}+\mathrm{sC}_{1}\right) \mathrm{V}_{\text {in } 6}}{\mathrm{~s}^{2} \mathrm{C}_{1} \mathrm{C}_{2}+\mathrm{sC}_{2} \mathrm{G}_{1}+\mathrm{G}_{2} \mathrm{G}_{3}} \\
& \mathrm{~V}_{\text {out } 1}=\frac{\mathrm{s}^{2} \mathrm{C}_{1} \mathrm{C}_{2} \mathrm{~V}_{\text {in } 1}-\mathrm{sC}_{2} \mathrm{G}_{2} \mathrm{~V}_{\text {in2 }}+\mathrm{sC}_{2} \mathrm{G}_{2} \mathrm{~V}_{\text {in } 3}+\mathrm{G}_{2} \mathrm{G}_{3} \mathrm{~V}_{\text {in } 4}-\mathrm{G}_{2} \mathrm{G}_{3} \mathrm{~V}_{\text {in } 5}}{\mathrm{~s}^{2} \mathrm{C}_{1} \mathrm{C}_{2}+\mathrm{sC}_{2} \mathrm{G}_{1}+\mathrm{G}_{2} \mathrm{G}_{3}}
\end{aligned}
$$




$$
V_{\text {out } 2}=\frac{-\mathrm{sC}_{1} \mathrm{G}_{3} \mathrm{~V}_{\text {in } 1}+\mathrm{G}_{2} \mathrm{G}_{3} \mathrm{~V}_{\text {in } 2}-\mathrm{G}_{2} \mathrm{G}_{3} \mathrm{~V}_{\text {in } 3}+\mathrm{G}_{3}\left(\mathrm{G}_{1}+\mathrm{s} \mathrm{C}_{1}\right) \mathrm{V}_{\text {in } 4}-\mathrm{G}_{3}\left(\mathrm{G}_{1}+\mathrm{sC}_{1}\right) \mathrm{V}_{\text {in } 5}}{\mathrm{~s}^{2} \mathrm{C}_{1} \mathrm{C}_{2}+\mathrm{sC}_{2} \mathrm{G}_{1}+\mathrm{G}_{2} \mathrm{G}_{3}}
$$

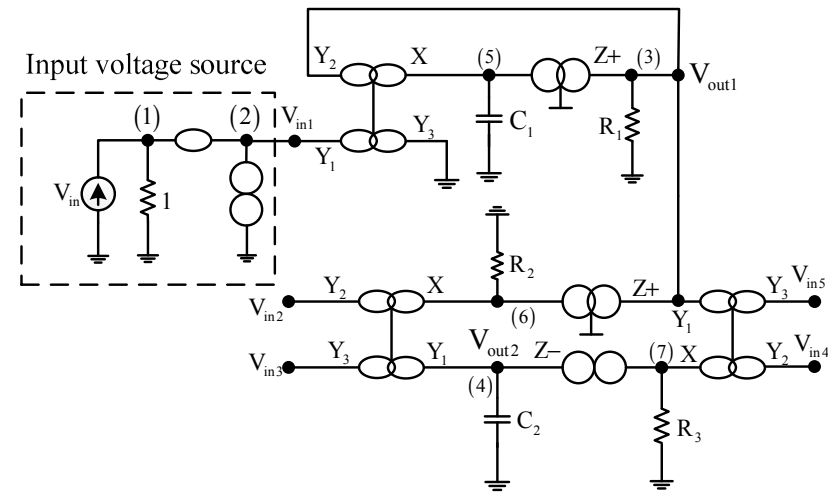

a)

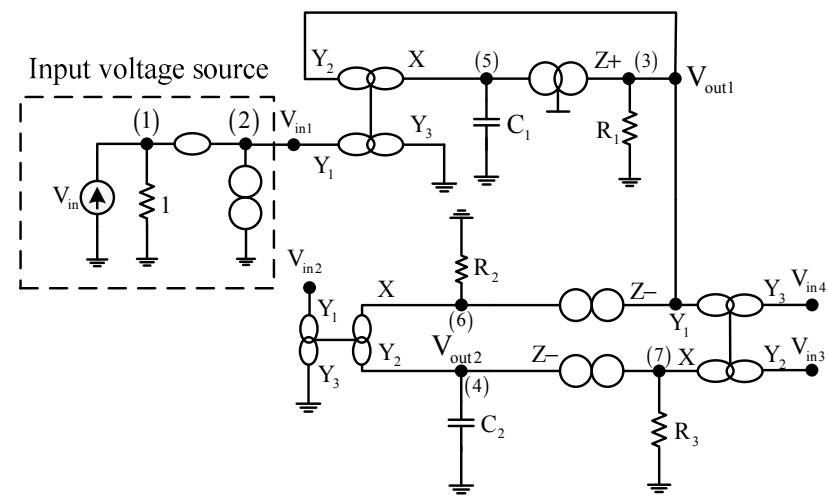

c)

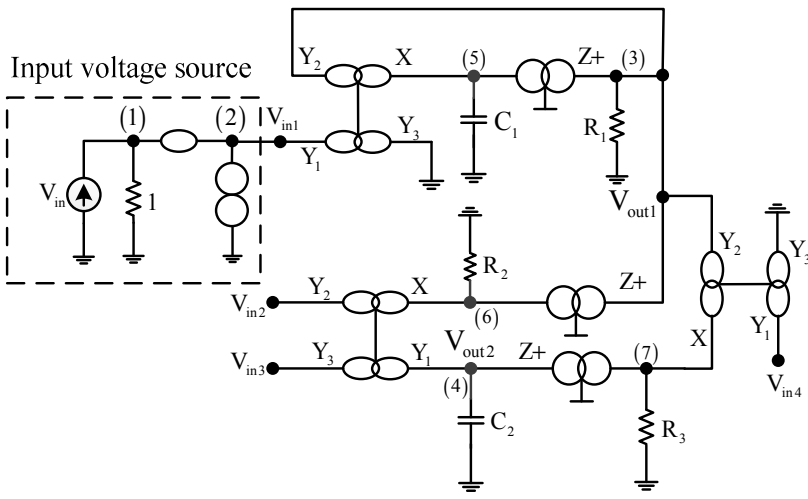

b)

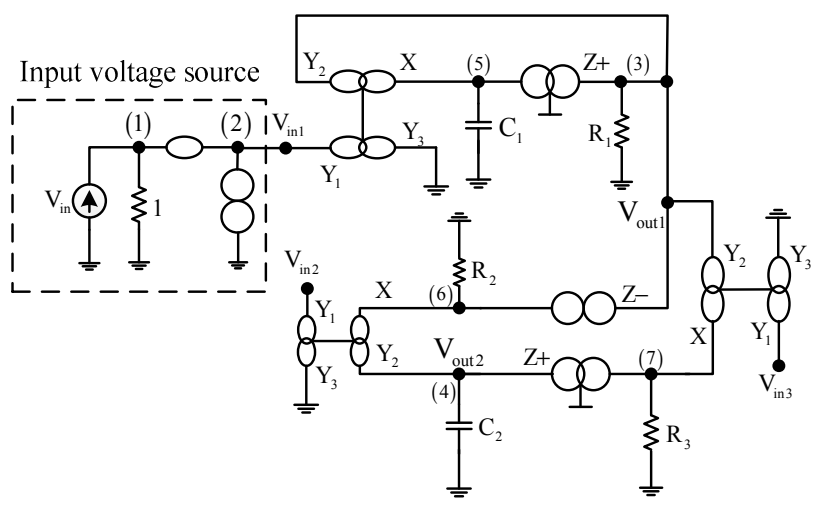

d)

Figure 4. The pathological representations of derived type-A filters (cases 5-8).

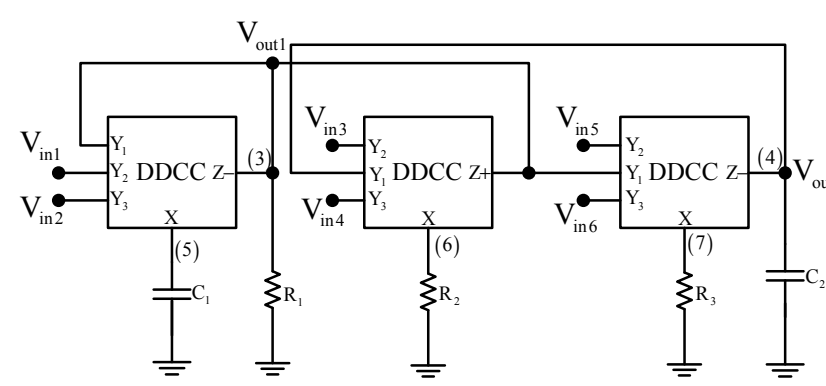

a)

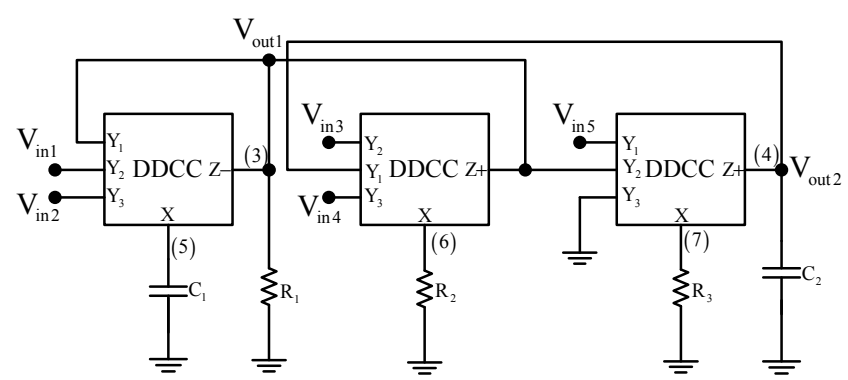

b)

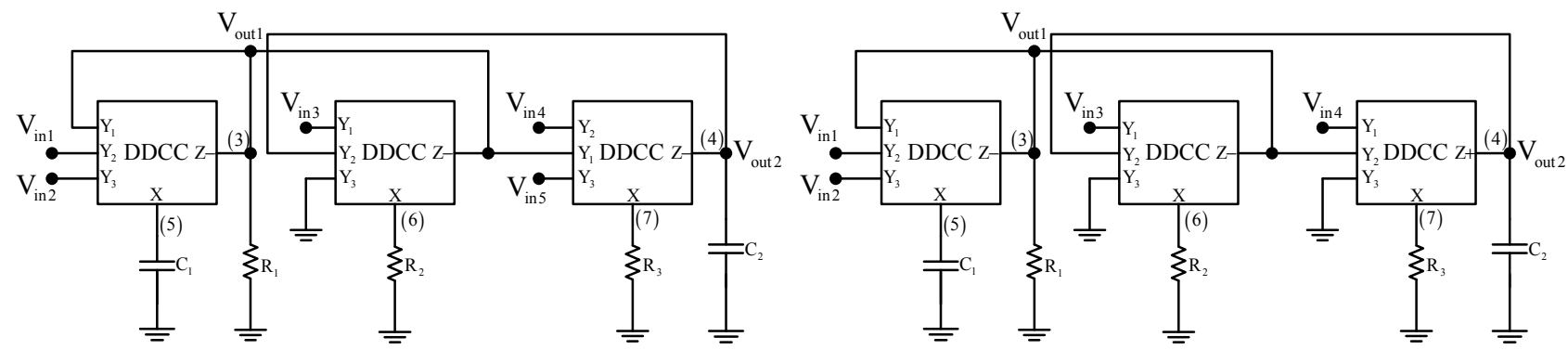

c)

d)

Figure 5. Cont. 


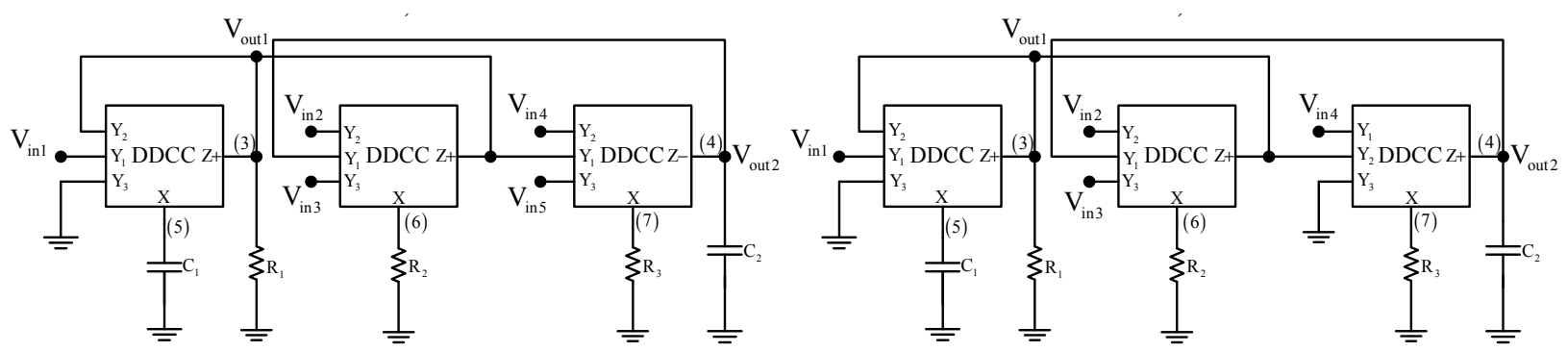

e)

f)

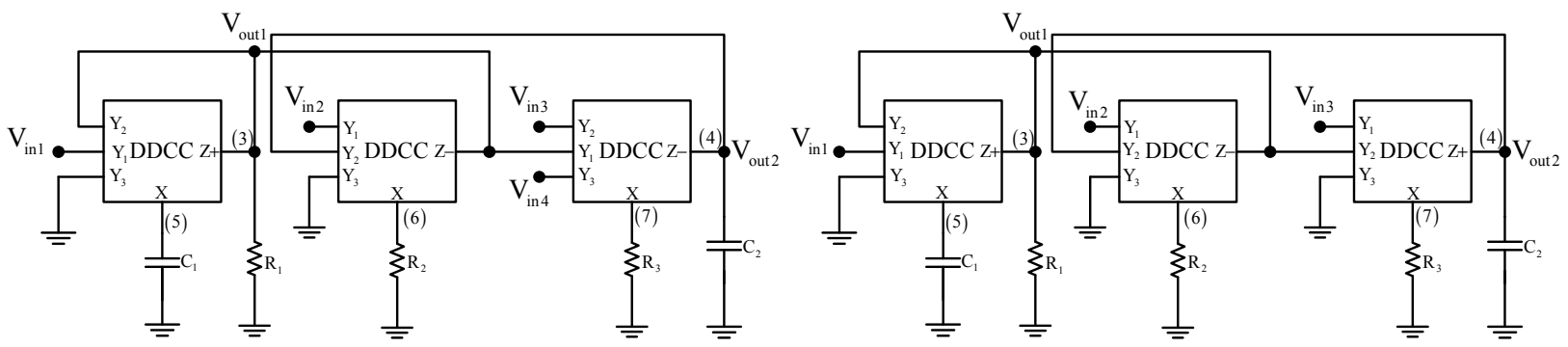

g)

h)

Figure 5. The practical configuration of type-A filters.

\subsection{Synthesis of Type-B Universal Filters}

Similarly, by applying Step 2, the equivalent NAMs (27) and (28) are obtained from (11). Applying Step 3, the Matrix (28) can be expanded as (29). There are four alternative cases (cases 1-4) that can be derived by expanding Matrix (28), as shown in Table 2.

$$
\begin{aligned}
& {\left[\begin{array}{ccc}
1 & 0 & 0 \\
0 & \mathrm{G}_{1}+\mathrm{sC}_{1} & \mathrm{G}_{2} \\
0 & -\mathrm{G}_{3} & \mathrm{sC}_{2}
\end{array}\right]} \\
& {\left[\begin{array}{cccc}
1 & 0 & 0 & 0 \\
-\infty_{1} & \infty_{1} & 0 & 0 \\
0 & 0 & \mathrm{G}_{1}+\mathrm{sC}_{1} & \mathrm{G}_{2} \\
0 & 0 & -\mathrm{G}_{3} & \mathrm{sC}_{2}
\end{array}\right]} \\
& {\left[\begin{array}{ccccccc}
1 & 0 & 0 & 0 & 0 & 0 & 0 \\
-\infty_{1} & \infty_{1} & 0 & 0 & 0 & 0 & 0 \\
0 & 0 & \mathrm{G}_{1}+\infty_{2} & \infty_{3} & -\infty_{2} & -\infty_{3} & 0 \\
0 & 0 & -\infty_{4} & \mathrm{sC}_{2} & 0 & 0 & \infty_{4} \\
0 & 0 & -\infty_{2} & 0 & \mathrm{sC}_{1}+\infty_{2} & 0 & 0 \\
0 & 0 & 0 & -\infty_{3} & 0 & \mathrm{G}_{2}+\infty_{3} & 0 \\
0 & 0 & -\infty_{4} & 0 & 0 & 0 & \mathrm{G}_{3}+\infty_{4}
\end{array}\right]}
\end{aligned}
$$


Table 2. Four cases of expanding NAM Type-B.

\begin{tabular}{|c|c|c|c|c|c|c|c|c|c|c|c|c|c|}
\hline \multicolumn{7}{|c|}{ NAM Type-B (Case 1) } & \multicolumn{7}{|c|}{ NAM Type-B (Case 2) } \\
\hline 1 & 0 & 0 & 0 & 0 & 0 & 0 & 1 & 0 & 0 & 0 & 0 & 0 & 0 \\
\hline$-\infty_{1}$ & $\infty_{1}$ & 0 & 0 & 0 & 0 & 0 & $-\infty$ & $\infty_{1}$ & 0 & 0 & 0 & 0 & 0 \\
\hline 0 & 0 & $\mathrm{G}_{1}+\infty_{2}$ & $\infty_{3}$ & $-\infty_{2}$ & $-\infty_{3}$ & 0 & 0 & 0 & $\mathrm{G}_{1}+\infty_{2}$ & $\infty_{3}$ & $-\infty_{2}$ & $-\infty_{3}$ & 0 \\
\hline 0 & 0 & $-\infty_{4}$ & $\mathrm{sC}_{2}$ & 0 & 0 & $\infty_{4}$ & 0 & 0 & $-\infty_{4}$ & $\mathrm{sC}_{2}$ & 0 & 0 & $-\infty_{4}$ \\
\hline 0 & 0 & $-\infty_{2}$ & 0 & $\mathrm{sC}_{1}+\infty_{2}$ & 0 & 0 & 0 & 0 & $-\infty_{2}$ & 0 & $\mathrm{sC}_{1}+\infty_{2}$ & 0 & 0 \\
\hline 0 & 0 & 0 & $-\infty_{3}$ & 0 & $\mathrm{G}_{2}+\infty_{3}$ & 0 & 0 & 0 & 0 & $-\infty_{3}$ & 0 & $\mathrm{G}_{2}+\infty_{3}$ & 0 \\
\hline 0 & 0 & $-\infty_{4}$ & 0 & 0 & 0 & $\mathrm{G}_{3}+\infty_{4}$ & 0 & 0 & $\infty_{4}$ & 0 & 0 & 0 & $\mathrm{G}_{3}+\infty_{4}$ \\
\hline \multicolumn{7}{|c|}{ NAM Type-B (Case 3) } & \multicolumn{7}{|c|}{ NAM Type-B (Case 4) } \\
\hline 1 & 0 & 0 & 0 & 0 & 0 & 0 & 1 & 0 & 0 & 0 & 0 & 0 & 0 \\
\hline$-\infty_{1}$ & $\infty_{1}$ & 0 & 0 & 0 & 0 & 0 & $-\infty$ & $\infty_{1}$ & 0 & 0 & 0 & 0 & 0 \\
\hline 0 & 0 & $\mathrm{G}_{1}+\infty_{2}$ & $\infty_{3}$ & $\infty_{2}$ & $-\infty_{3}$ & 0 & 0 & 0 & $\mathrm{G}_{1}+\infty_{2}$ & $\infty_{3}$ & $\infty_{2}$ & $-\infty_{3}$ & 0 \\
\hline 0 & 0 & $-\infty_{4}$ & $\mathrm{sC}_{2}$ & 0 & 0 & $\infty_{4}$ & 0 & 0 & $-\infty_{4}$ & $\mathrm{sC}_{2}$ & 0 & 0 & $-\infty_{4}$ \\
\hline 0 & 0 & $\infty_{2}$ & 0 & $\mathrm{sC}_{1}+\infty_{2}$ & 0 & 0 & 0 & 0 & $\infty_{2}$ & 0 & $\mathrm{sC}_{1}+\infty_{2}$ & 0 & 0 \\
\hline 0 & 0 & 0 & $-\infty_{3}$ & 0 & $\mathrm{G}_{2}+\infty_{3}$ & 0 & 0 & 0 & 0 & $-\infty_{3}$ & 0 & $\mathrm{G}_{2}+\infty_{3}$ & 0 \\
\hline 0 & 0 & $-\infty_{4}$ & 0 & 0 & 0 & $\mathrm{G}_{3}+\infty_{4}$ & 0 & 0 & $\infty_{4}$ & 0 & 0 & 0 & $\mathrm{G}_{3}+\infty_{4}$ \\
\hline
\end{tabular}

In (29), the $\operatorname{DDCC}(1), \operatorname{DDCC}(2)$ and $\operatorname{DDCC}(3)$ are represented by terms $\pm \infty_{2}, \pm \infty 3$ and $\pm \infty 4$, respectively. The terminal-X of $\mathrm{DDCC}(1)$ can be node 5 , terminal- $Y_{1}$ and terminal-Z (minus type) are connected to node 3 . For the $\operatorname{DDCC}(2)$, terminal-X is connected to node 6 , terminal- $Y_{1}$ is connected to node 4 and terminal-Z (minus type) is connected to node 3. For the $\operatorname{DDCC}(3)$, the terminal-X is connected to node 7 , terminal- $Y_{1}$ is connected to node 3 and terminal-Z (plus type) is connected to node 4. All of the terminal- $Y_{2}$ and terminal- $Y_{3}$ of $\operatorname{DDCC}(1), \operatorname{DDCC}(2)$ and $\operatorname{DDCC}(3)$ can be used to inject the input voltage source.

Applying Step 4 , term $-\mathrm{sC}_{1}$ will be created in position $(2,1)$ of $(27)$ by injecting the input voltage source to terminal- $\mathrm{Y}_{2}$ of the $\operatorname{DDCC}(1)$, then a highpass function at $\mathrm{V}_{\text {out1 }}$ and bandpass function at $\mathrm{V}_{\text {out2 }}$ can be obtained. This operation corresponds to the insertion of the term $\pm \infty_{2}$ to the second column of (29), as shown in (30). The obtained filter represented by (30) is shown in Figure 6a with nodes $V_{\text {in2, }}$ $\mathrm{V}_{\text {in3 }}, \mathrm{V}_{\text {in } 4}, \mathrm{~V}_{\text {in5 }}$ and $\mathrm{V}_{\text {in6 }}$ being grounded.

$$
\left[\begin{array}{ccccccc}
1 & 0 & 0 & 0 & 0 & 0 & 0 \\
-\infty_{1} & \infty_{1} & 0 & 0 & 0 & 0 & 0 \\
0 & -\infty_{2} & \mathrm{G}_{1}+\infty_{2} & \infty_{3} & -\infty_{2} & -\infty_{3} & 0 \\
0 & 0 & -\infty_{4} & \mathrm{sC}_{2} & 0 & 0 & \infty_{4} \\
0 & \infty_{2} & -\infty_{2} & 0 & \mathrm{sC}_{1}+\infty_{2} & 0 & 0 \\
0 & 0 & 0 & -\infty_{3} & 0 & \mathrm{G}_{2}+\infty_{3} & 0 \\
0 & 0 & -\infty_{4} & 0 & 0 & 0 & \mathrm{G}_{3}+\infty_{4}
\end{array}\right]
$$

By injecting the input voltage source to terminal- $Y_{3}$ of $\operatorname{DDCC}(1)$, the admittance matrix is shown in (31) and the obtained transfer functions at node $V_{\text {out1 }}$ and $V_{\text {out2 }}$ are identical to that obtained in (30) with reverse signs. The obtained circuit is shown in Figure 6a, moving the injected voltage source equivalent circuit to node $V_{\text {in2 }}$ and grounding nodes $V_{\text {in1 } 1, ~} V_{\text {in3 }}$, $V_{\text {in4 }}, V_{\text {in5 }}$ and $V_{\text {in6. }}$ 


$$
\left[\begin{array}{ccccccc}
1 & 0 & 0 & 0 & 0 & 0 & 0 \\
-\infty_{1} & \infty_{1} & 0 & 0 & 0 & 0 & 0 \\
0 & \infty_{2} & \mathrm{G}_{1}+\infty_{2} & \infty_{3} & -\infty_{2} & -\infty_{3} & 0 \\
0 & 0 & -\infty_{4} & \mathrm{sC}_{2} & 0 & 0 & \infty_{4} \\
0 & -\infty_{2} & -\infty_{2} & 0 & \mathrm{sC}_{1}+\infty_{2} & 0 & 0 \\
0 & 0 & 0 & -\infty_{3} & 0 & \mathrm{G}_{2}+\infty_{3} & 0 \\
0 & 0 & -\infty_{4} & 0 & 0 & 0 & \mathrm{G}_{3}+\infty_{4}
\end{array}\right]
$$

Also, by applying the input voltage source to terminal-Y2 of $\operatorname{DDCC}(2)$, a bandpass function at $\mathrm{V}_{\text {out }}$ and a lowpass function at $\mathrm{V}_{\text {out2 }}$ can be obtained. This is equivalent to the inserting of term $\pm \infty \infty_{3}$ to the second column of (29), as shown in (32). The obtained filter is shown in Figure 6a, moving the injected voltage source equivalent circuit to node $V_{\text {in3 }}$ and grounding nodes $V_{\text {in1 }}, V_{\text {in2, }} V_{\text {in4 }}, V_{\text {in5 }}$ and $V_{\text {in6. }}$

$$
\left[\begin{array}{ccccccc}
1 & 0 & 0 & 0 & 0 & 0 & 0 \\
-\infty_{1} & \infty_{1} & 0 & 0 & 0 & 0 & 0 \\
0 & -\infty_{3} & \mathrm{G}_{1}+\infty_{2} & \infty_{3} & -\infty_{2} & -\infty_{3} & 0 \\
0 & 0 & -\infty_{4} & \mathrm{sC}_{2} & 0 & 0 & \infty_{4} \\
0 & 0 & -\infty_{2} & 0 & \mathrm{sC}_{1}+\infty_{2} & 0 & 0 \\
0 & \infty_{3} & 0 & -\infty_{3} & 0 & \mathrm{G}_{2}+\infty_{3} & 0 \\
0 & 0 & -\infty_{4} & 0 & 0 & 0 & \mathrm{G}_{3}+\infty_{4}
\end{array}\right]
$$

Injecting the input voltage source to terminal-Y $Y_{3}$ of $\operatorname{DDCC}(2)$, the obtained transfer functions at nodes $V_{\text {out1 }}$ and $V_{\text {out2 }}$ are identical to that obtained in (32) but with different signs, as shown in (33). The derived filter is shown in Figure 6a by moving the injected voltage source equivalent circuit to node $\mathrm{V}_{\text {in }}$ with grounding nodes $\mathrm{V}_{\text {in1 }}, \mathrm{V}_{\text {in2}}, \mathrm{V}_{\text {in3 }}, \mathrm{V}_{\text {in5 }}$ and $\mathrm{V}_{\text {in6. }}$

Besides, a lowpass function at $\mathrm{V}_{\text {out1 }}$ can be achieved by applying the input voltage source to terminal- $Y_{2}$ of DDCC(3). This operation corresponds to the inserting of terms $\infty_{4}$ to the second column of (29), as given in (34). The obtained circuit is shown in Figure 6a by moving the injected voltage source equivalent circuit to node $V_{\text {in5 }}$ and grounding nodes $V_{\text {in1 }}, V_{\text {in2}}, V_{\text {in3 }}, V_{\text {in4 }}$ and $V_{\text {in6. }}$

$$
\left[\begin{array}{ccccccc}
1 & 0 & 0 & 0 & 0 & 0 & 0 \\
-\infty_{1} & \infty_{1} & 0 & 0 & 0 & 0 & 0 \\
0 & \infty_{3} & \mathrm{G}_{1}+\infty_{2} & \infty_{3} & -\infty_{2} & -\infty_{3} & 0 \\
0 & 0 & -\infty_{4} & \mathrm{sC}_{2} & 0 & 0 & \infty_{4} \\
0 & 0 & -\infty_{2} & 0 & \mathrm{sC}_{1}+\infty_{2} & 0 & 0 \\
0 & -\infty_{3} & 0 & -\infty_{3} & 0 & \mathrm{G}_{2}+\infty_{3} & 0 \\
0 & 0 & -\infty_{4} & 0 & 0 & 0 & \mathrm{G}_{3}+\infty_{4}
\end{array}\right]
$$




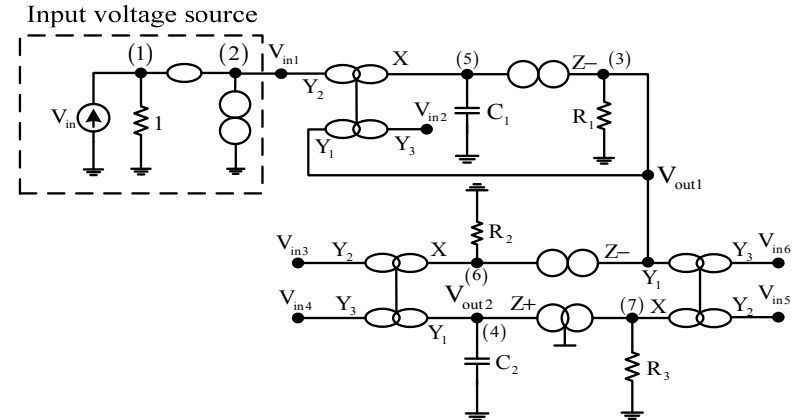

a)

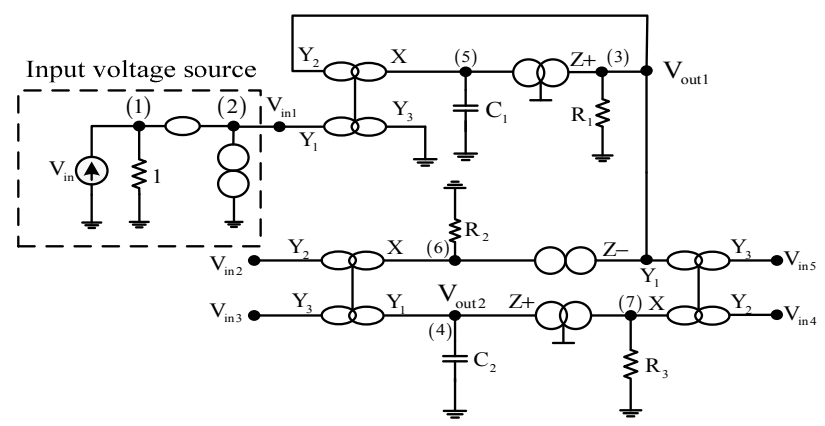

c)

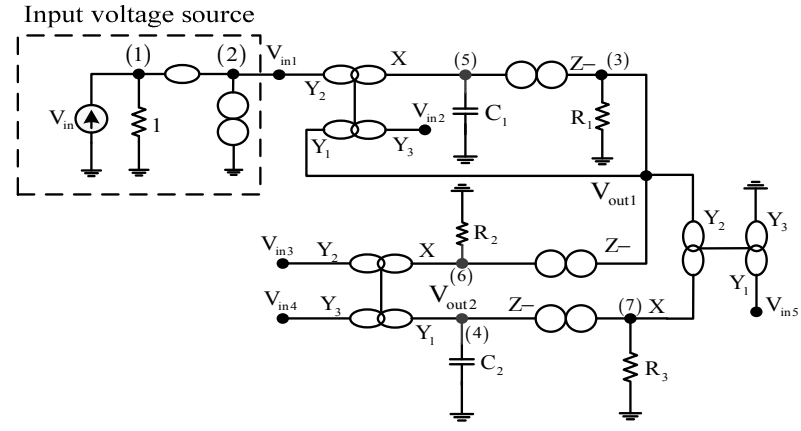

b)

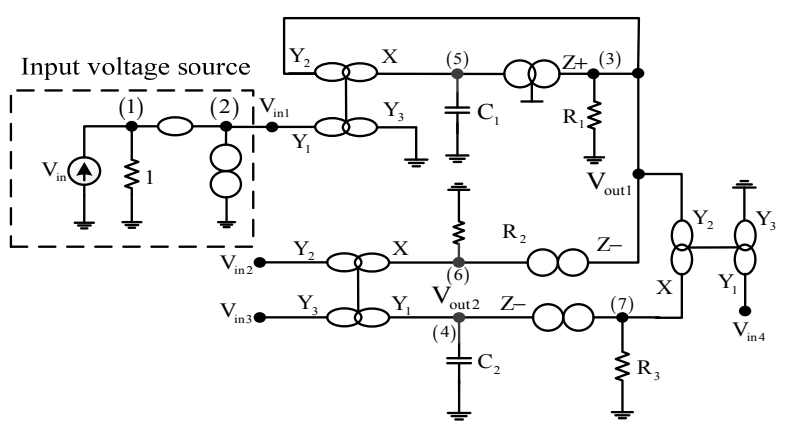

d)

Figure 6. The pathological representations of type-B filters.

$$
\left[\begin{array}{ccccccc}
1 & 0 & 0 & 0 & 0 & 0 & 0 \\
-\infty_{1} & \infty_{1} & 0 & 0 & 0 & 0 & 0 \\
0 & 0 & \mathrm{G}_{1}+\infty_{2} & \infty_{3} & -\infty_{2} & -\infty_{3} & 0 \\
0 & \infty_{4} & -\infty_{4} & \mathrm{sC}_{2} & 0 & 0 & \infty_{4} \\
0 & 0 & -\infty_{2} & 0 & \mathrm{sC}_{1}+\infty_{2} & 0 & 0 \\
0 & 0 & 0 & -\infty_{3} & 0 & \mathrm{G}_{2}+\infty_{3} & 0 \\
0 & \infty_{4} & -\infty_{4} & 0 & 0 & 0 & \mathrm{G}_{3}+\infty_{4}
\end{array}\right]
$$

Injecting the input voltage source to terminal- $Y_{3}$ of $\operatorname{DDCC}(3)$, the obtained transfer function at node $\mathrm{V}_{\text {out } 1}$ is identical to the circuit represented by (34) with reverse signs. The obtained matrix is shown in (35) and the circuit is shown in Figure 6a by moving the injected voltage source equivalent circuit to node $\mathrm{V}_{\text {in6 }}$ with grounding nodes $\mathrm{V}_{\text {in1 }}, \mathrm{V}_{\text {in2 }}, \mathrm{V}_{\text {in } 3}, \mathrm{~V}_{\text {in } 4}$ and $\mathrm{V}_{\text {in5 }}$ grounded.

$$
\left[\begin{array}{ccccccc}
1 & 0 & 0 & 0 & 0 & 0 & 0 \\
-\infty_{1} & \infty_{1} & 0 & 0 & 0 & 0 & 0 \\
0 & 0 & \mathrm{G}_{1}+\infty_{2} & \infty_{3} & -\infty_{2} & -\infty_{3} & 0 \\
0 & -\infty_{4} & -\infty_{4} & \mathrm{sC}_{2} & 0 & 0 & \infty_{4} \\
0 & 0 & -\infty_{2} & 0 & \mathrm{sC}_{1}+\infty_{2} & 0 & 0 \\
0 & 0 & 0 & -\infty_{3} & 0 & \mathrm{G}_{2}+\infty_{3} & 0 \\
0 & -\infty_{4} & -\infty_{4} & 0 & 0 & 0 & \mathrm{G}_{3}+\infty_{4}
\end{array}\right]
$$

Different type-B filter functions at $\mathrm{V}_{\text {out1 }}$ and $\mathrm{V}_{\text {out2 }}$ can be obtained by using similar method as mentioned in Section 3.1. The notch function at $V_{\text {out1 }}$ can be achieved by injecting the input voltage 
source to terminal- $Y_{2}$ of DDCC(1) and terminal- $Y_{2}$ of DDCC(3). The obtained filter is shown in Figure 6 a by moving the injected voltage source equivalent circuit to the merged node of $V_{\text {in } 1}$ and $V_{\text {ins }}$

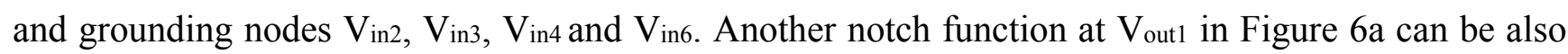
obtained by injecting the input voltage source to the merged node of $V_{\text {in2 }}$ and $V_{\text {in6 }}$ with nodes $V_{\text {in1 }}, V_{\text {in } 3 \text {, }}$ $V_{\text {in } 4}$ and $V_{\text {in } 5}$ being grounded. Similarly, an allpass function at $V_{\text {out1 }}$ (with $G_{2}=G_{1}$ ) can be achieved by injecting the input voltage source to terminal- $Y_{2}$ of DDCC(1), terminal- $Y_{3}$ of DDCC(2) and terminal- $Y_{2}$ of DDCC(3). The obtained circuit is shown in Figure 6a by moving the injected voltage source equivalent circuit to the merged node of $V_{\text {in1 }}, V_{\text {in } 4}$ and $V_{\text {in5 }}$ and grounding nodes $V_{\text {in2, }} V_{\text {in3 } 3}$ and $V_{\text {in6. }}$ Another allpass function at $\mathrm{V}_{\text {out1 }}$ can be also obtained by injecting the input voltage source to the merged node of $V_{\text {in2}}, V_{\text {in } 3}$ and $V_{\text {in6 }}$ in Figure 6a with nodes $V_{\text {in1 }}, V_{\text {in4 }}$ and $V_{\text {in } 5}$ being grounded.

In the same way, the above synthesized procedure can be applied to other matrices in Table 2. Four equivalent circuits of synthesized filters are shown in Figure 6. The transfer functions of the synthesized circuit for the case 1 of Table 2 are given by (36) and (37). Figure 7 shows the practical configurations realizing the pathological equivalents in Figure 6. Table 3 shows the comparison of obtained filters using the proposed method and related systematic synthesis approaches $[16,17,19,21]$. It clarifies the benefits of the proposed method.

$$
\begin{gathered}
V_{\text {out } 1}=\frac{s^{2} C_{1} C_{2} V_{\text {in } 1}-s^{2} C_{1} C_{2} V_{\text {in } 2}+s_{2} C_{2} V_{2} V_{\text {in } 3}-s C_{2} G_{2} V_{\text {in } 4}+G_{2} G_{3} V_{\text {in } 5}-G_{2} G_{3} V_{\text {in } 6}}{s^{2} C_{1} C_{2}+s C_{2} G_{1}+G_{2} G_{3}} \\
V_{\text {out } 2}=\frac{s C_{1} G_{3} V_{\text {in1 } 1}-s_{1} G_{3} V_{\text {in } 2}+G_{2} G_{3} V_{\text {in } 3}-G_{2} G_{3} V_{\text {in } 4}-G_{3}\left(G_{1}+s C_{1}\right) V_{\text {in } 5}+G_{3}\left(G_{1}+s C_{1}\right) V_{\text {in } 6}}{s^{2} C_{1} C_{2}+s C_{2} G_{1}+G_{2} G_{3}}
\end{gathered}
$$

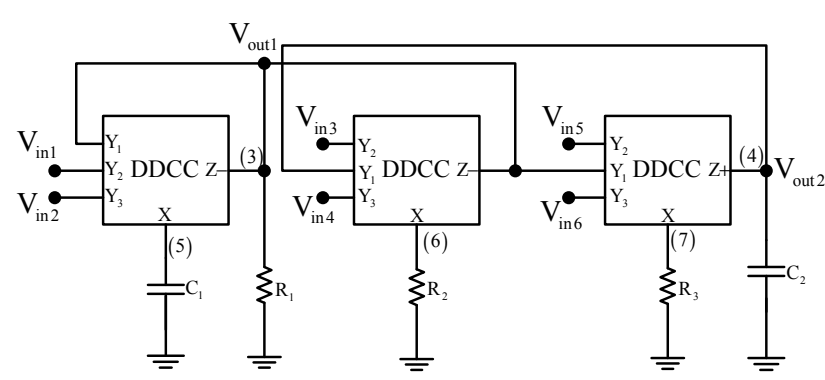

a)

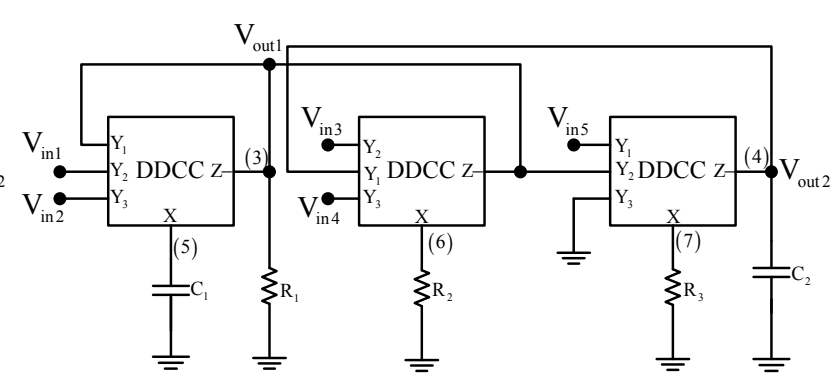

b)

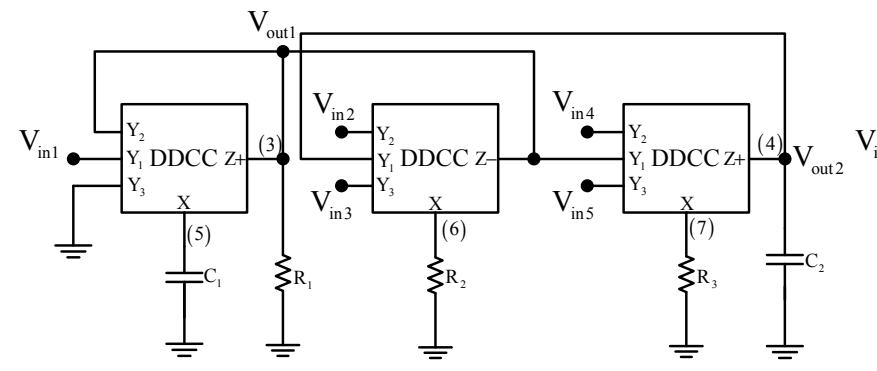

c)

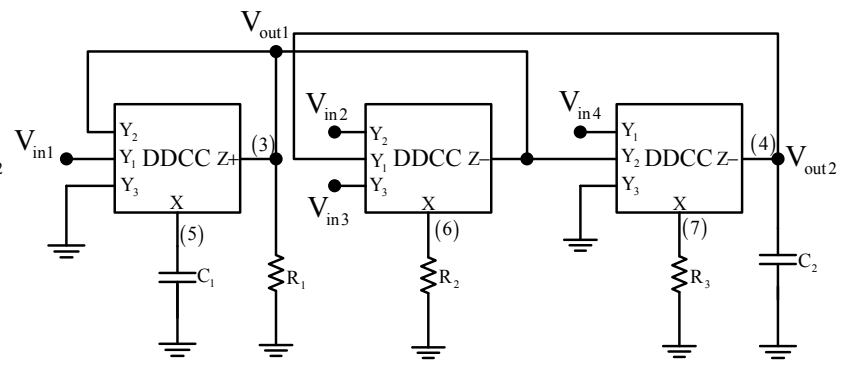

d)

Figure 7. The practical configuration of type-B filters. 
Table 3. Comparison of the obtained filter of related works.

\begin{tabular}{cccccc}
\hline $\begin{array}{c}\text { Related } \\
\text { work }\end{array}$ & $\begin{array}{c}\text { Operating } \\
\text { mode }\end{array}$ & Filter type & $\begin{array}{c}\text { Using grounded } \\
\text { capacitors }\end{array}$ & $\begin{array}{c}\text { Number of active } \\
\text { elements }\end{array}$ & $\begin{array}{c}\text { Cascadable } \\
\text { property }\end{array}$ \\
\hline$[16]$ & Current & Universal & Yes & 4 & Yes \\
{$[17]$} & Transimpedance & Single function & No & 1 or 2 & Yes \\
{$[19]$} & Voltage & Notch & No & 3 & No \\
{$[21]$} & Voltage & $\begin{array}{c}\text { Lowpass and } \\
\text { bandpass }\end{array}$ & Yes & 2 & Yes \\
This work & Voltage & Universal & Yes & 3 & Yes \\
\hline
\end{tabular}

\subsection{Non-Ideal Effect of Active Elements}

Taking into account the non-idealities of DDCCs, the relationship of the terminal voltages and currents is given as

$$
\left[\begin{array}{c}
\mathrm{V}_{\mathrm{X}} \\
\mathrm{I}_{\mathrm{Y} 1} \\
\mathrm{I}_{\mathrm{Y} 2} \\
\mathrm{I}_{\mathrm{Y} 3} \\
\mathrm{I}_{\mathrm{Z}}
\end{array}\right]=\left[\begin{array}{cccc}
\alpha_{\mathrm{k} 1} & -\alpha_{\mathrm{k} 2} & \alpha_{\mathrm{k} 3} & 0 \\
0 & 0 & 0 & 0 \\
0 & 0 & 0 & 0 \\
0 & 0 & 0 & 0 \\
0 & 0 & 0 & \pm \beta_{\mathrm{k}}
\end{array}\right]\left[\begin{array}{c}
\mathrm{V}_{\mathrm{Y} 1} \\
\mathrm{~V}_{\mathrm{Y} 2} \\
\mathrm{~V}_{\mathrm{Y} 3} \\
\mathrm{I}_{\mathrm{X}}
\end{array}\right]
$$

where $\alpha_{\mathrm{k} 1}, \alpha_{\mathrm{k} 2}$ and $\alpha_{\mathrm{k} 3}$ respectively denote the voltage tracking errors from $\mathrm{V}_{\mathrm{Y} 1}$ to $\mathrm{V}_{\mathrm{X}}, \mathrm{V}_{\mathrm{Y} 2}$ to $\mathrm{V}_{\mathrm{X}}$, and $\mathrm{V}_{\mathrm{Y} 3}$ to $\mathrm{VX}_{\mathrm{X}}$ of the $k$ th DDCC; and $\beta_{\mathrm{k}}$ denotes the current tracking error of the $k$ th DDCC. The denominator of non-ideal transfer function of all obtained filters can be expressed by (39).

$$
\mathrm{D}(\mathrm{s})=\alpha_{1 \mathrm{i}} \beta_{1} \mathrm{~s}^{2} \mathrm{C}_{1} \mathrm{C}_{2}+\mathrm{sC}_{2} \mathrm{G}_{1}+\alpha_{2 \mathrm{j}} \alpha_{3 \mathrm{k}} \beta_{2} \beta_{3} \mathrm{G}_{2} \mathrm{G}_{3}
$$

where $i, j, k=1-2$. The pole frequency $\omega_{0}$ and the $\mathrm{Q}$ factor are expressed by (40) and (41), respectively. The active and passive sensitivities of $\omega_{0}$ and $Q$ of all obtained filters are shown in (42). It can be seen that all active and passive sensitivities are small.

$$
\begin{gathered}
\omega_{0}=\sqrt{\frac{\alpha_{2 j} \alpha_{3 \mathrm{k}} \beta_{2} \beta_{3} \mathrm{G}_{2} \mathrm{G}_{3}}{\alpha_{1 \mathrm{i}} \beta_{1} \mathrm{C}_{1} \mathrm{C}_{2}}} \\
\mathrm{Q}=\frac{1}{\mathrm{G}_{1}} \sqrt{\frac{\alpha_{1 \mathrm{i}} \alpha_{2 \mathrm{j}} \alpha_{3 \mathrm{k}} \beta_{1} \beta_{2} \beta_{3} \mathrm{C}_{1} \mathrm{G}_{2} \mathrm{G}_{3}}{\mathrm{C}_{2}}} \\
\mathrm{~S}_{\mathrm{G}_{2}, \mathrm{G}_{3}}^{\omega_{0}}=-\mathrm{S}_{\mathrm{C}_{1}, \mathrm{C}_{2}}^{\omega_{0}}=\mathrm{S}_{\mathrm{C}_{1}, \mathrm{G}_{2}, \mathrm{G}_{3}}^{\mathrm{Q}}=-\mathrm{S}_{\mathrm{C}_{2}}^{\mathrm{Q}}=\frac{1}{2} ; \\
\mathrm{S}_{\mathrm{G}_{1}}^{\mathrm{Q}}=-1 ; \mathrm{S}_{\beta_{2}, \beta_{3}}^{\omega_{0}}=\mathrm{S}_{\beta_{1}, \beta_{2}, \beta_{3}}^{\mathrm{Q}}=\frac{1}{2} ; \mathrm{S}_{\beta_{1}}^{\omega_{0}}=-\frac{1}{2} ; \\
\mathrm{S}_{\alpha_{2 \mathrm{j}}, \alpha_{3 \mathrm{k}}}^{\omega_{0}}=\mathrm{S}_{\alpha_{1 \mathrm{i}}, \alpha_{2 \mathrm{j}}, \alpha_{3 \mathrm{k}}}^{\mathrm{Q}}=\frac{1}{2} ; \mathrm{S}_{\alpha_{1 \mathrm{i}}}^{\omega_{0}}=-\frac{1}{2} ;
\end{gathered}
$$




\section{Simulation Results}

To verify the workability of the proposed method, HSPICE simulations using TSMC $0.35 \mu \mathrm{m}$ process parameters were performed for two of the obtained type-A and type-B filters. The CMOS implementation of the DDCC shown in Figure 8 was used for the simulations [27]. The aspect ratios of each NMOS and PMOS transistor are $(\mathrm{W} / \mathrm{L}=5 \mu \mathrm{m} / 1 \mu \mathrm{m})$ and $(\mathrm{W} / \mathrm{L}=10 \mu \mathrm{m} / 1 \mu \mathrm{m})$, respectively. The supply voltages of DDCC are $\mathrm{V}_{\mathrm{DD}}=-\mathrm{V}_{\mathrm{SS}}=1.65 \mathrm{~V}$ with the biasing voltages $\mathrm{V}_{\mathrm{B}}=-\mathrm{V}_{\mathrm{B} 1}=0.76 \mathrm{~V}$.

We simulated the filters in Figure $5 \mathrm{f}$ (type-A) and Figure $7 \mathrm{~b}$ (type-B) for illustration. The values of capacitors are chosen as $\mathrm{C}_{1}=\mathrm{C}_{2}=10 \mathrm{pF}$ for all simulations. The values of resistors are given by $\mathrm{R}_{1}=11.26 \mathrm{k} \Omega$ and $\mathrm{R}_{2}=\mathrm{R}_{3}=15.92 \mathrm{k} \Omega$ for the simulations of lowpass, bandpass and highpass filters. Figure 9 and Figure 10 show the lowpass and bandpass responses at $V_{\text {out1 }}$ and $V_{\text {out2 }}$ of the filter in Figure $5 \mathrm{f}$ with node $V_{\text {in } 3}$ as input node and nodes $V_{\text {in1 }}, V_{\text {in2 }}$, and $V_{\text {in } 4}$ being ground node. The frequency responses of highpass output in Figure $5 f$ with node $V_{\text {in1 }}$ as input node and nodes $V_{\text {in2, }} V_{\text {in3 }}$, and $V_{\text {in }}$ being grounded is shown in Figure 11. Figure 12 shows the notch responses at $\mathrm{V}_{\text {out1 }}$ of the circuit in Figure $7 b$, with the merged node of $V_{\text {in1 }}$ and $V_{\text {in } 5}$ as input node and nodes $V_{\text {in2}}, V_{\text {in3 }}$ and $V_{\text {in4 }}$ being ground node, and $\mathrm{R}_{1}=79.62 \mathrm{k} \Omega, \mathrm{R}_{2}=\mathrm{R}_{2}=\mathrm{R}_{3}=15.92 \mathrm{k} \Omega$. Figure 13 represents the frequency responses of the allpass function in Figure $7 \mathrm{~b}$ with the merged node of $V_{\text {in1 }}, V_{\text {in } 4 \text {, and }} V_{\text {in5 }}$ as input node and $V_{\text {in2 }}$ and $V_{\text {in } 3}$ grounded. The $\mathrm{R}_{1}=\mathrm{R}_{2}=11.26 \mathrm{k} \Omega$ and $\mathrm{R}_{3}=22.52 \mathrm{k} \Omega$ is used. All the simulated results are consistent with our theoretical prediction. The workability of the synthesized filters is verified.

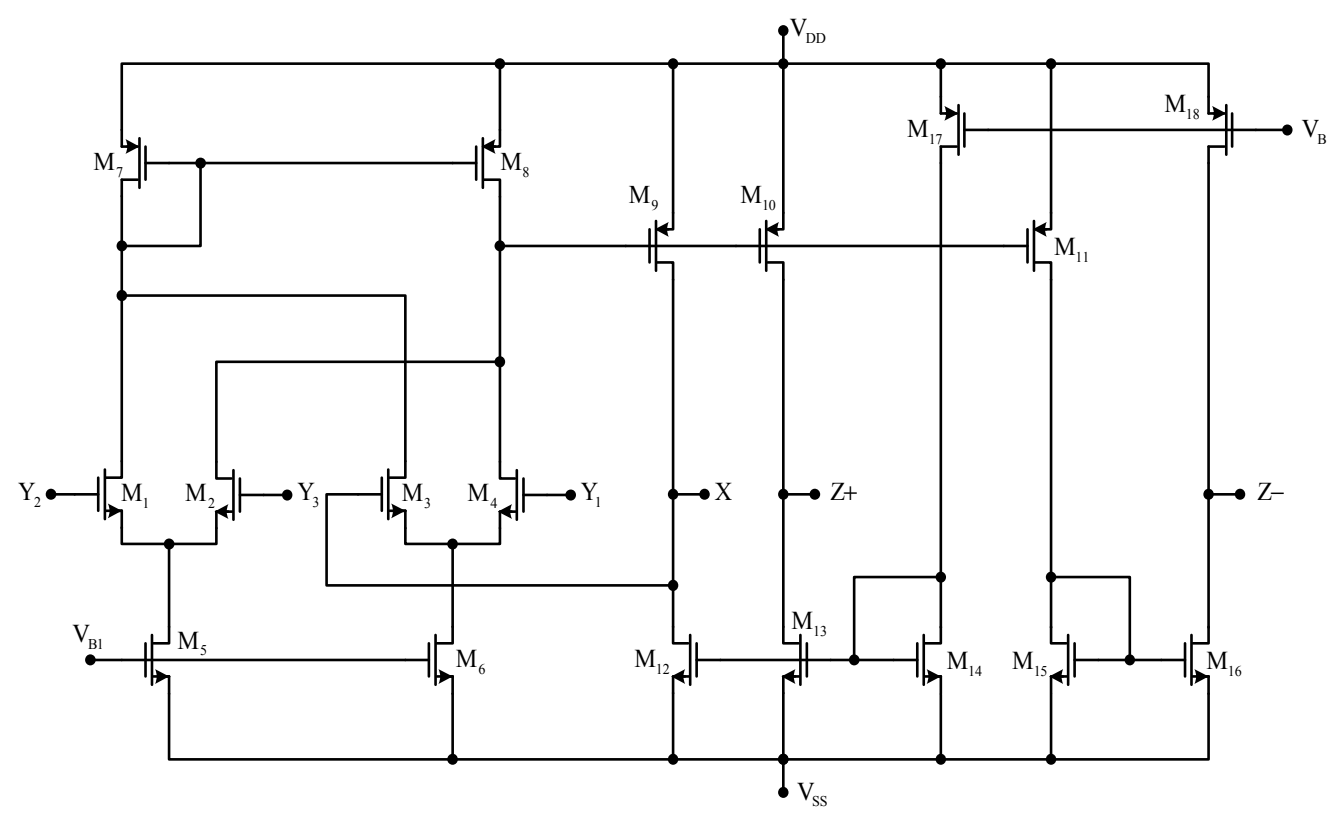

Figure 8. The CMOS circuit of DDCC [27]. 


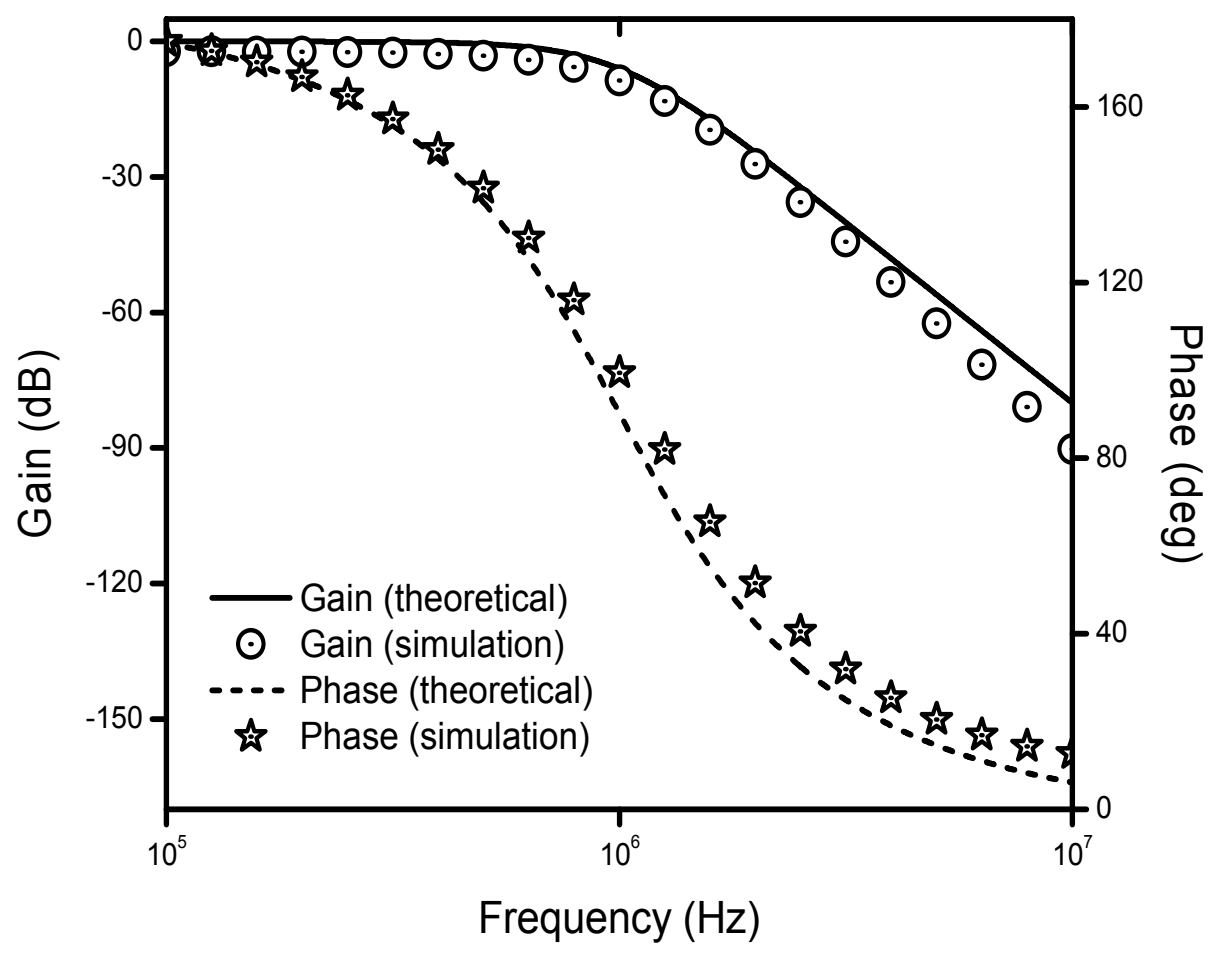

Figure 9. Frequency responses of the lowpass function in Figure $5 f$.

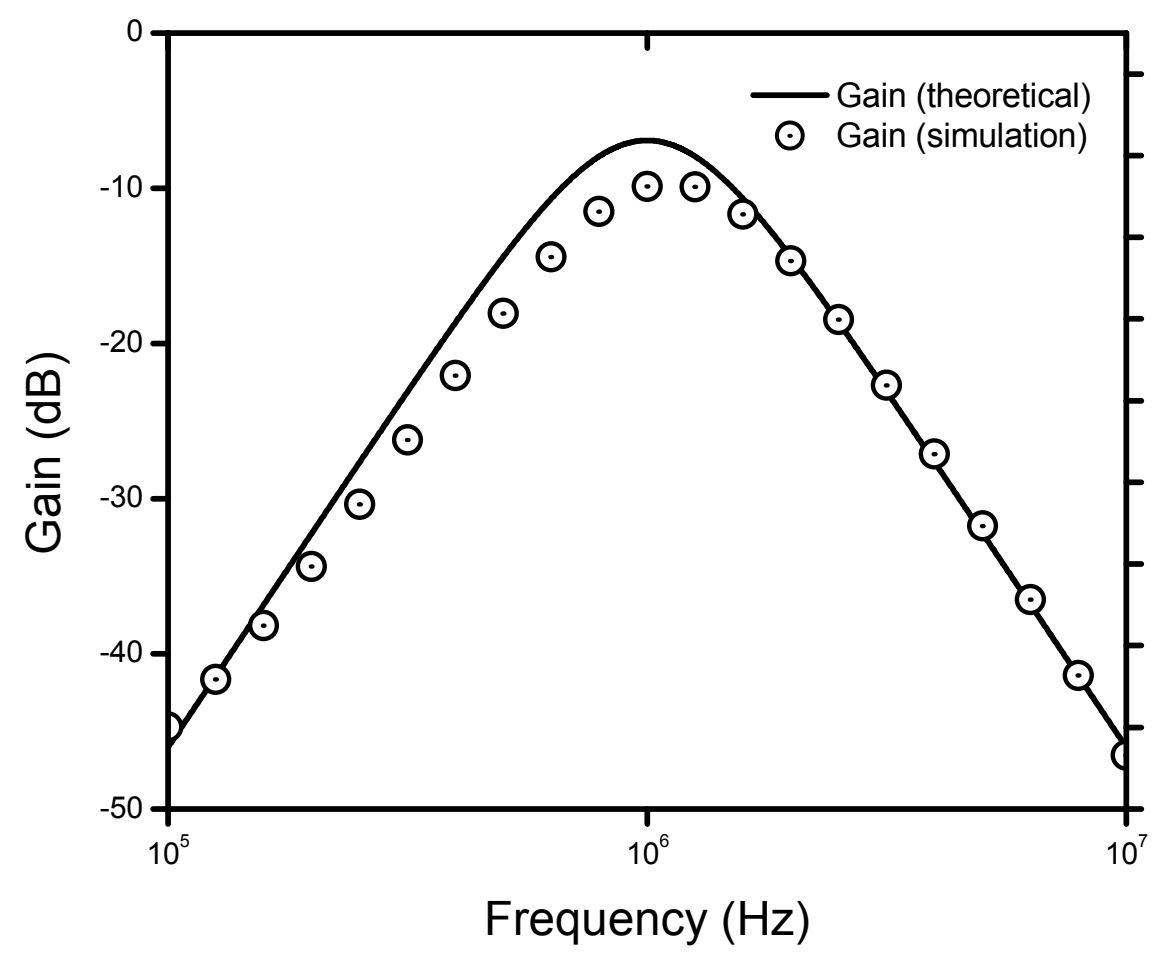

Figure 10. Frequency responses of the bandpass function in Figure $5 f$. 


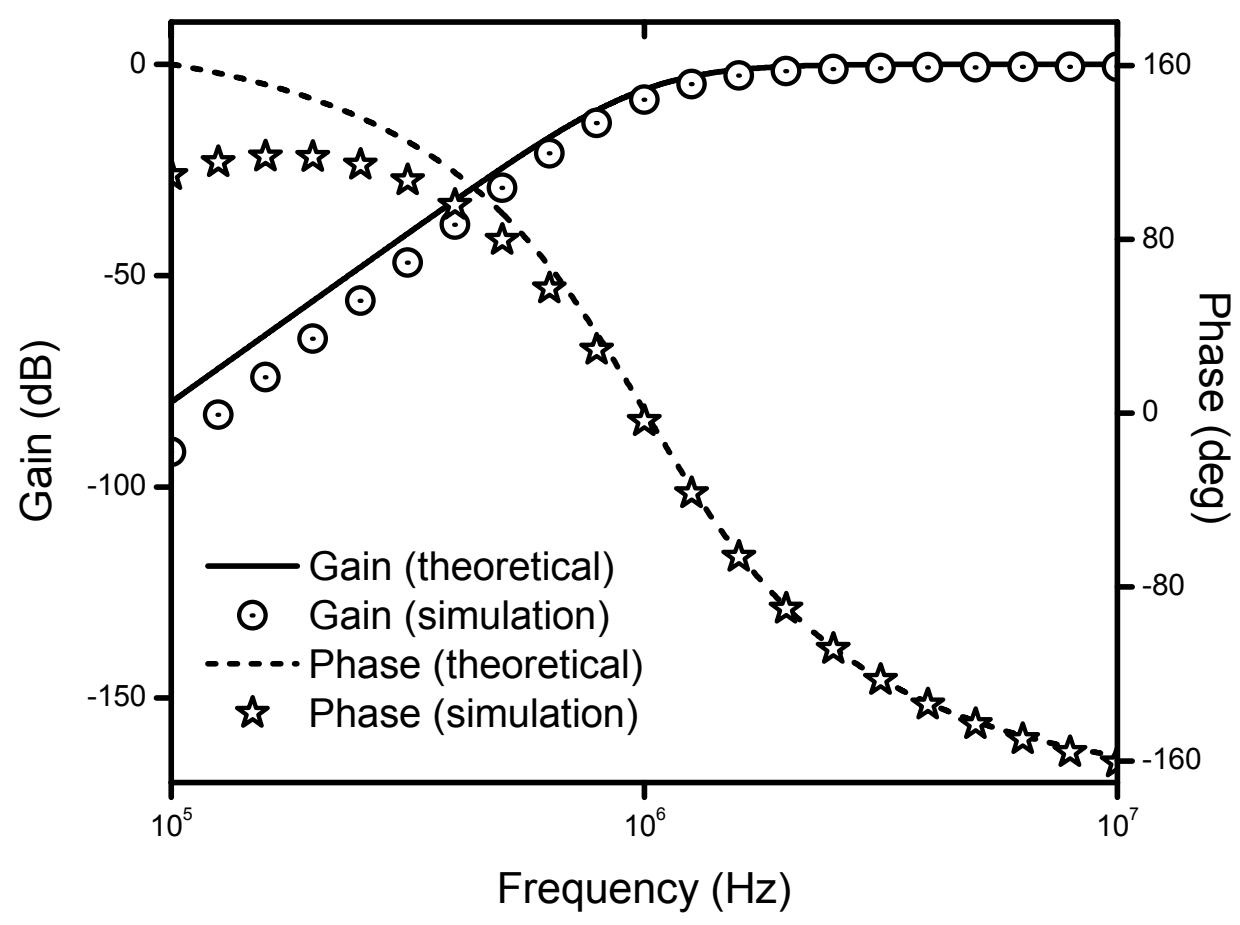

Figure 11. Frequency responses of the highpass function in Figure $5 \mathrm{f}$.

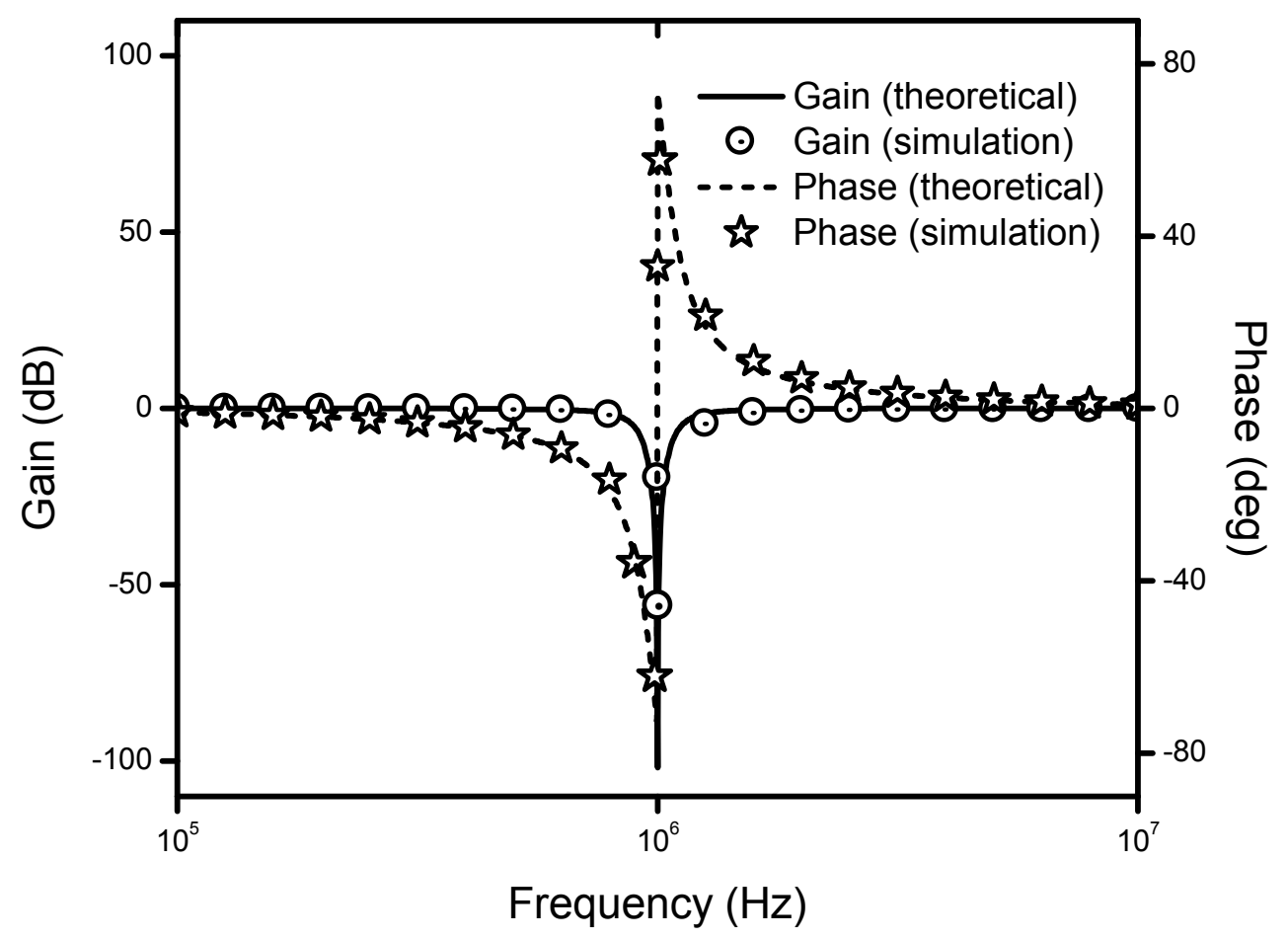

Figure 12. Frequency responses of the notch function in Figure $7 \mathrm{~b}$. 


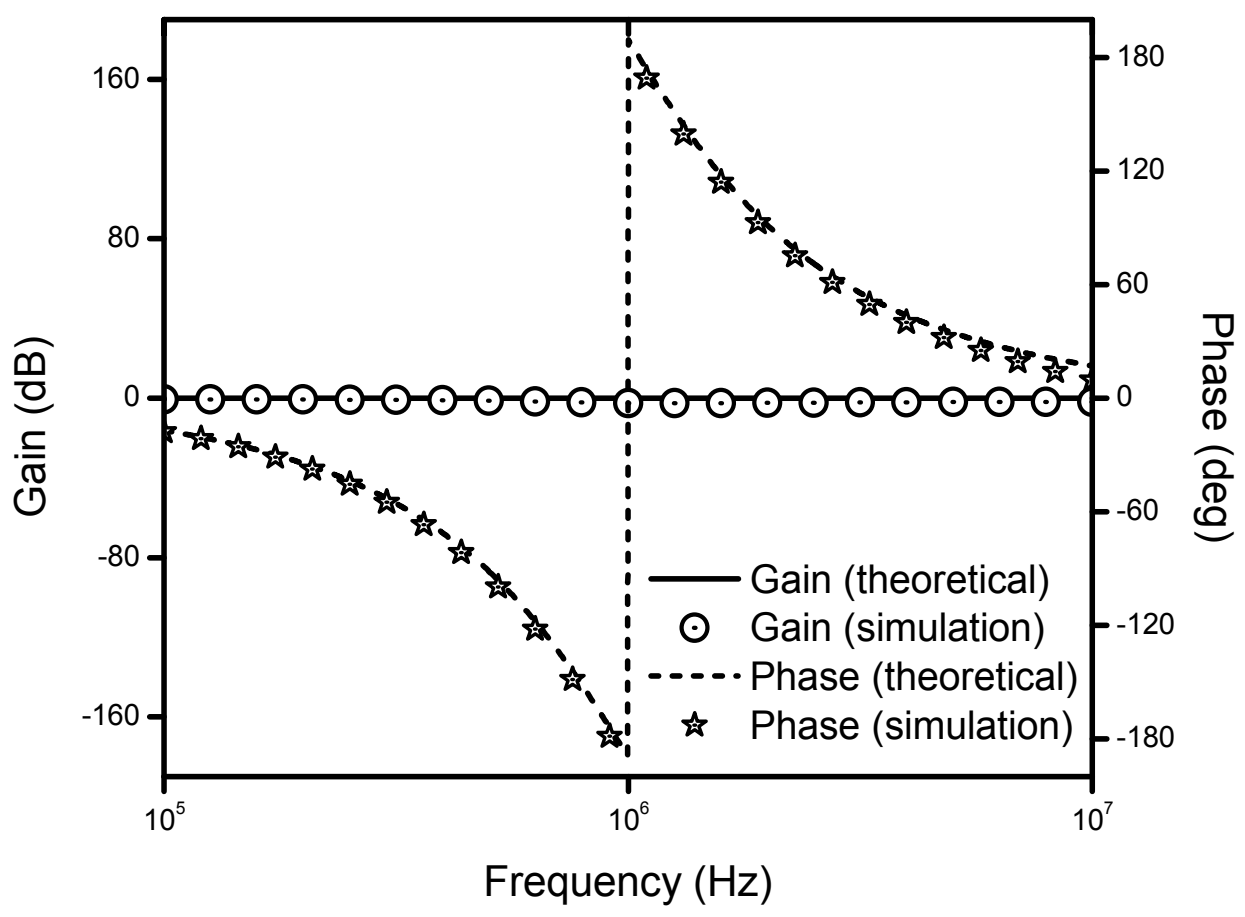

Figure 13. Frequency responses of the allpass function in Figure $7 \mathrm{~b}$.

\section{Conclusions}

Based on the infinity-variables notation of the DDCC and NAM expansion technique, a systematic method for synthesis of voltage-mode DDCC-based universal biquadratic filters is proposed. The obtained filters with two outputs can realize all five generic filter functions. They have the properties of high-input impedance, employing only grounded capacitors and resistors, orthogonal controllability between pole frequency and quality factor, and low active and passive sensitivities. HSPICE simulated results show the workability of the synthesized circuits, and the feasibility of the proposed approach is confirmed.

\section{Acknowledgments}

This work has been supported by the Ministry of Science and Technology of the Republic of China (Grant No. MOST 103-2221-E-151-060).

\section{Author Contributions}

Huu-Duy Tran and Quoc-Minh Nguyen conceived and designed the theoretical verifications; the optimization ideas were provided by Min-Chuan Lin; Hung-Yu Wang and Huu-Duy Tran analyzed the results and wrote the paper.

\section{Conflicts of Interest}

The authors declare no conflict of interest. 


\section{References}

1. Fabre, F.; Dayoub, L.; Duruisseau, L.; Kamoun, M. High-input impedance insensitive second-order filters implemented from current conveyors. IEEE Trans. Circuits Syst. I 1994, 41, 918-921.

2. Chen, H.P. Single CCII-based voltage-mode universal filter. Analog Integr. Circuits Signal Process. 2010, 62, 259-262.

3. Horng, J.W. High-input impedance voltage-mode universal biquadratic filters with three inputs using plus-type CCIIs. Int. J. Electron. 2004, 91, 465-475.

4. Chen, H.P. Single FDCCII-based universal voltage-mode filter. AEU-Int. J. Electron. Commun. 2009, 63, 713-719.

5. Horng, J.W. High-input impedance voltage-mode universal biquadratic filters using three plus-type CCIIs. IEEE Trans. Circuits Syst. II 2001, 48, 996-997.

6. Chen, H.P. Voltage-mode FDCCII-based universal filter. AEU-Int. J. Electron. Commun. 2008, 62, 320-323.

7. Horng, J.W.; Hou, C.L.; Chang, C.M.; Chou, H.P.; Lin, C.T. High-input impedance voltage-mode universal biquadratic filter with one input and five outputs using current conveyors. Circuits Syst. Signal Process. 2006, 25, 767-777.

8. Horng, J.W.; Hou, C.L.; Chang, C.M.; Chung, W.Y.; Wei, H.Y. Voltage-mode universal biquadratic filters with one input five outputs using MOCCIIs. Comput. Electr. Eng. 2005, 31, 190-202.

9. Chang, C.M.; Tu, S.H. Universal voltage mode filter with four inputs and one output using two CCII+s. Int. J. Electron. 1999, 86, 305-309.

10. Chang, C.M. Multifunction biquadratic filters using current conveyors. IEEE Trans. Circuits Syst. II 1997, 44, 956-958.

11. Haigh, D.G.; Clarke, T.J.W.; Radmore, P.M. Symbolic framework for linear active circuits based on port equivalence using limit variables. IEEE Trans. Circuits Syst. I 2006, 53, 2011-2024.

12. Haigh, D.G. A method of transformation from symbolic transfer function to active-RC circuit by admittance matrix expansion. IEEE Trans. Circuits Syst. I 2006, 53, 2715-2728.

13. Haigh, D.G.; Tan, F.Q.; Papavassiliou, C. Systematic synthesis of active-RC circuit building-blocks. Analog Integr. Circuits Signal Process. 2005, 43, 297-315.

14. Haigh, D.G.; Radmore, P.M. Admittance matrix models for the nullor using limit variables and their application to circuit design. IEEE Trans. Circuits Syst. I 2006, 53, 2214-2223.

15. Saad, R.A.; Soliman, A.M. Use of mirror elements in the active device synthesis by admittance matrix expansion. IEEE Trans. Circuits Syst. I 2008, 55, 2726-2735.

16. Soliman, A.M. Generation of current mode filters using NAM expansion. Int. J. Circuit Theory Appl. 2011, 39, 1087-1103.

17. Tan, L.; Bai, Y.; Teng, J.; Liu, K.; Meng, W. Trans-impedance filter synthesis based on nodal admittance matrix expansion. Circuits Syst. Signal Process. 2013, 32, 1467-1476.

18. Li, Y.A. NAM expansion method for systematic synthesis of floating gyrators using CCCCTAs. Analog Integr. Circuits Signal Process. 2015, 82, 733-743. 
19. Tran, H.D.; Wang, H.Y.; Nguyen, Q.M.; Chiang, N.H.; Lin, W.C.; Lee, T.F. High-Q biquadratic notch filter synthesis using nodal admittance matrix expansion. AEU-Int. J. Electron. Commun. 2015, 69, 981-987.

20. Li, Y.A. On the systematic synthesis of OTA-based Wien Oscillators. AEU-Int. J. Electron. Commun. 2013, 67, 754-760.

21. Soliman, A.M. Two integrator loop filters: Generation using NAM expansion and review. J. Electri. Comput. Eng. 2010, doi:org/10.1155/2010/108687.

22. Chiu, W.; Liu, S.I.; Tsao, H.W.; Chen, J.J. CMOS differential difference current conveyors and their applications. IEE Proc. Circuits Devices Syst. 1996, 143, 91-96.

23. Chiu, W.Y.; Horng, J.W. High-input and low-output impedance voltage-mode universal biquadratic filter using DDCCs. IEEE Trans. Circuits Syst. II 2007, 54, 649-652.

24. Chen, H.P. Universal voltage-mode filter using only plus-type DDCCs. Analog Integr. Circuits Signal Process. 2007, 50, 137-139.

25. Horng, J.W. High input impedance voltage-mode universal biquadratic filter with three inputs using DDCCs. Circuits Syst. Signal Process. 2008, 27, 553-562.

26. Chiu, W.Y.; Horng, J.W. High input impedance voltage-mode biquadratic filter with three inputs and six outputs using three DDCCs. Circuits Syst. Signal Process. 2012, 31, 19-30.

27. Elwan, H.O.; Soliman, A.M. Novel CMOS differential voltage current conveyor and its applications. IEE Proc. Circuits Devices Syst. 1997, 144, 195-200.

(C) 2015 by the authors; licensee MDPI, Basel, Switzerland. This article is an open access article distributed under the terms and conditions of the Creative Commons Attribution license (http://creativecommons.org/licenses/by/4.0/). 